\title{
El Gobierno Corporativo, ¿en el Ecuador?
}

\begin{abstract}
El término gobierno corporativo es análogo al gobierno de las naciones o de las ciudades, y en nuestro caso al régimen de las empresas. Es el conjunto de elementos que rodean e interactúan en la política de la sociedad mercantil, y su pleno funcionamiento con el fin de obtener las mayores utilidades corporativas a corto y largo plazo.
\end{abstract}

\section{Introducción}

Nadie olvidará el llamado "salvataje bancario" (1998) y el mal denominado "feriado bancario" (8-III1999), que conllevó al congelamiento de fondos y la crisis financiera más importante del Ecuador. El feriado bancario y la hibernación de las cuentas fue la crónica de la caída anunciada del presidente Jamil Mahuad ${ }^{1}$; cuando la moneda del "sucre", creada en 1884, pasaría al olvido por el cambio y legalización al dólar estadounidense como única moneda de curso legal ${ }^{2}$. Esta crisis resaltó la quiebra, liquidación y estatización de la banca ecuatoriana incluyendo a los Bancos del Azuay, Continental, Pacífico, Popular, La Previsora, Progreso, de Préstamos, Filanbanco, Tungurahua, etc. ${ }^{3}$ Millones de cuenta ahorristas perdieron sus inversiones o pasaron a recibir "su dinero" a cuentagotas, mientras la mayoría de los banqueros-propietarios (accionistas de control) y gerentes, se dieron a la fuga y refugiándose en el extranjero. Los banqueros fueron perseguidos por la justicia y enjuiciados por delitos perseguibles de oficio, en especial bajo la figura penal del peculado ${ }^{4}$. Sin embrago, ningún acreedor o accionista que demando por la vía procesal civil ordinaria, ha obtenido una sentencia favorable por quebrantamiento de los deberes fiduciarios de los administradores de la banca cerrada.

En otros países también ocurren escándalos corporativos y bancarios. Tenemos, por citar algunos, la crisis financiera asiática de 1998, y más reciente, la debacle de Enron (EE.UU.), Worldcom (EE.UU.), Marconi (UK), Royal Ahold (Holanda), ABB (Suecia), Parmalat (Italia), Volskwagen (Alemania), BBVA (España), Sibneft (Rusia), Daewoo (Corea del Sur), Koito Manufacturing Ltd. (Japón), TV Azteca (Méjico), etc. De aquí, emergió una importante crítica sobre los directores y supervisores corporativos, que tienen el papel de gatekeepers o fiscalizadores de las sociedades.

Es aquí donde entra el gobierno corporativo o corporate governance, tema principal de este trabajo. El título I presentó la introducción. El título II definirá y enmarcará al gobierno corporativo en el mundo y en nuestro país. A continuación el título III discurre sobre las más relevantes teorías de gobierno corporativo, y las teorías de gestión de las empresas. El título IV profundiza los principales dilemas del gobierno corporativo para las compañías ecuatorianas. Por último, el título $\mathrm{V}$ concluye y presenta las recomendaciones.

\section{Concepto de Gobierno Corporativo y Códigos de Buen Gobierno}

Richard EELLS fue el primero en utilizar la terminología "gobierno de la buena empresa o gobierno corporativo"s (GC) para referirse al gobierno societario. Empero, no existe una definición única de ésta materia, por lo que incluimos entre las más destacadas las siguientes: Andrei SHLIFER y Robert W. VISHNY definen al gobierno corporativo, como las formas y medios a través de los cuales quienes proporcionan fondos financieros se aseguran de una retribución adecuada a sus inversiones ${ }^{6}$. Para Luigi ZINGALES, el gobierno corporativo es el complejo conjunto de circunstancias que configuran la negociación a posteriori de las cuasi-rentas generadas por la compañía ${ }^{7}$. También está expresión de GC, que alude a un movimiento de reforma de la estructura del poder decisorio en las grandes sociedades anónimas. Dicho movimiento se concreta en la propuesta de un amplio conjunto de medidas, que tiene por objeto remediar los problemas derivados de la disociación, existente en las referidas sociedades, entre propiedad (accionistas) y poder (administradores ejecutivos), para de ese modo garantizar una gestión social eficiente ${ }^{8}$.

El término gobierno corporativo es análogo al gobierno de las naciones o de las ciudades, y en nuestro caso al 
régimen de las empresas. Definimos al GC como el conjunto de elementos que rodean e interactúan en la política de la sociedad mercantil, y su pleno funcionamiento con el fin de obtener las mayores utilidades corporativas a corto y largo plazo (beneficios presentes y futuros), donde intervienen, chocan y afectan su actividad de particular manera los socios (propietarios) y los administradores u órgano de administración (gestores), donde a su vez participan los acreedores, los trabajadores, los auditores externos, los reguladores de bolsa, los tribunales de justicia, el Estado, los clientes y el mismo mercado. El gobierno corporativo afecta, en lo principal, a sociedades bursátiles, pero su aplicación no es exclusiva o excluyente a sociedades anónimas cerradas y a compañías de responsabilidad limitada.

La normatividad jurídica que enmarca de manera cardinal el Derecho de Sociedades ecuatoriano son la Ley de Compañías ( $\mathrm{LC}^{9}$ ); Ley de Mercado de Valores (LMV10); Ley General de Instituciones del Sistema Financiero (LGISFil); Reglamentos y resoluciones de la Superintendencia de Compañías ${ }^{12}$; Reglamentos y resoluciones de la Superintendencia de Bancos y Seguros; Reglamentos y resoluciones del Consejo Nacional de Valores (CNV13); Código de Comercio (CCom ${ }^{14}$ ); Código Civil (CC ${ }^{15}$ ); Estatuto de la Bolsa de Valores ${ }^{16}$; y, Estatuto social de cada empresa.

Desde el punto de vista metodológico, el movimiento de metamorfosis del gobierno de las sociedades, ha sido canalizado por medio de los denominados códigos de mejores prácticas corporativas o códigos éticos de buen gobierno (CGC), que han proliferado en muchos países en los últimos años, como ha sido por ejemplo en: Alemania17, Australia ${ }^{18}$, Bangladesh ${ }^{19}$, Brasil ${ }^{20}$, China $^{21}$, Colombia 22 , España ${ }^{23}$, Francia ${ }^{24}$, Italia ${ }^{25}$, Japón ${ }^{26}$, México ${ }^{27}$, los Países Bajos ${ }^{28}$, Perú29, el Reino Unido $\left(\mathrm{UK}^{30}\right)$, la Unión Europea ${ }^{31}$, etc. Los EE.UU. aprobaron la Sarbanes-Oxley Act (2002) ${ }^{32}$, la cual modificó normas de aplicación por parte de sociedades cotizadas, y entre otras medidas, obligó la creación de un comité de auditoría (audit committee), un comité de elección y retribución a los directivos (nominating committee), y la duración, nombramiento y rotación de los auditores externos.

En el contexto de nuestra nación, el Comité Ejecutivo Nacional de Buen Gobierno Corporativo (CEN), aprobó y adoptó el 13-I-2005, el Código de Buen Gobierno Corporativo, con el patrocinio de a Corporación Andina de Fomento (CAF), la Bolsa de Valores de Quito (BVQ), entre otros ${ }^{33}$; basándose en los Lineamientos para un Código Andino de Gobierno Corporativo o Código Andino de Gobierno Corporativo (CAGC) presentado por la CAF en 2004. El CAGC es un código voluntario donde las empresas que se adscriben y se comprometen a aplicar unas buenas prácticas corporativas ${ }^{34}$.

El Código de Buen Gobierno Corporativo Ecuatoriano $(\mathrm{CEc})$ contiene las 51 medidas o recomendaciones tomadas del CAGC, el cual esta basado en el White Paper sobre Gobierno Corporativo en América Latina $(2000,2004)$, elaborado por la Organización para la
Cooperación y el Desarrollo Económico (OECD), y otros CGC ya citados.

El CEc regula, en lo principal: 1. Los derechos y trato equitativo de los accionistas, en especial el de los accionistas minoritarios. 2. La integración y las reuniones de la Junta General de Accionistas o de Socios. 3. La composición del directorio o junta directiva. 4. La responsabilidad de los administradores, directores y altos ejecutivos. 5. La publicidad, transparencia informativa y comunicación de los hechos corporativos. 6. El control e información de los estados contables-financieros. 7. El papel de los auditores externos. 8. La función de los grupos de control. 9. La elaboración, aprobación y publicación de un informe anual de CG. 10. El uso de arbitraje como mecanismo de solución de controversias entre la sociedad y los accionistas.

El buen GC es crítico para el sector privado que está encaminado hacia al crecimiento económico y al mejoramiento del bienestar, que depende del incremento de las inversiones, eficiencia del mercado de capitales y desempeño de las compañías ${ }^{35}$.

\section{Teorías de Gobierno Corporativo y Teorías de Gestión de las Sociedades}

\section{Teorías de Gobierno Corporativo}

¿Porqué algunos países tienen mercados de capital más grandes que otros? (véase el Gráfico 1). Algunas teorías intentan explicar este vital asunto. Emerge entonces la pregunta, ¿cómo los países pueden implantar un mejor sistema de GC? Antes de describir las teorías de GC, existen en el mundo dos mecanismos generalizados para la obtención del financiamiento del capital societario, mecanismos que se han desarrollado a base de propias circunstancias culturales, sociales e históricas. Estos dos mecanismos prevalecientes son: (i) la banca ("Bank centered" system) o, (ii) el mercado de capitales ("Market centered" system).

(i) Primero, el marco corporativo asiático, hispano y europeísta-continental se organizó en el "control-interno" ("insider/control-oriented") de las sociedades mercantiles, bajo la supervisón del banco gestor versus el gobierno corporativo sajón, caracterizado por un "control-externo" ("outsider/arm's-length") ${ }^{36}$. En el primer caso, los recursos dinerarios en países como Ecuador, Francia, Italia y Japón, el canon es la banca universal que presta todos los servicios financieros, incluyendo los fondos mutuos y prestaciones de inversión, a través de filiales o sociedades del mismo banco ${ }^{37}$. Las características privativas de los países civilistas luego de la posguerra, promovió la creación de grupos de sociedades por medio de participaciones recíprocas (cross-shareholdings), y la necesidad de proteger la promesa del empleo de por vida de los trabajadores, conllevando al blindaje de los administradores y accionistas de control; como sucede en el chaebol coreano ${ }^{38}$, el keiretsu y el mochiai japonés ${ }^{39}$. 
En consecuencia, la banca se conformó en el principal contingente de supervisión y control de las compañías, disciplinando a los directores o gerentes de las personas jurídicas (y sus grupos empresariales), por medio de la degradación de los préstamos financieros o de los escándalos corporativos. Es así que el sistema de 'bancos' denota el control concentrado de familias en grandes empresas y 'holdings' como sucede en Austria, Canadá, Italia y Alemania ${ }^{40}$. Hoy en día, por citar el caso germano, el acceso a la información interna de una empresa la obtienen los acreedores al ser miembros con voto del consejo de supervisión (supervisory board) ${ }^{41}$. Aunque éste tipo vigilancia del contingente bancario, en la práctica, ha sido efímera generando un mal desempeño de las compañías, como es el caso japonés ${ }^{42}$.

(ii) Por otra parte y como segundo mecanismo, los Estados Unidos de Norteamérica (EE.UU.) y el Reino Unido (UK), se construyeron bajo la fundación de un mercado de capital (capital market or market centered economy), donde los dispersos accionistas necesitaban mayores y mejores incentivos para protegerse ellos mismos- de los administradores, puesto que no lo harían los bancos (ya que no controlan a sus clientes-sociedades). En los países sajones, la activa supervisión por parte de dichos accionistas dispersos se da por medio del otorgamiento de gran información al público y al mercado de valores sobre el estado de las sociedades, y la posible presión externa de los accionistas utilizando los tribunales. Como explica Law \& Finance, los derechos de voto de un accionista (oneshare-one-vote; o una-acción-un-voto) son desiguales entre los variados regímenes corporativos diseñados para proteger el control familiar ${ }^{43}$. Por ejemplo, el FMI y el Banco Mundial recomendaron a posteriori a la crisis financiera Asiática (1997-1998), además de políticas macroeconómicas tradicionales (como la reducción del déficit público gubernamental), reformar la estructura del sistema de gobierno corporativo hacia el modelo norteamericano 44 . Equivalentemente, los cambios tecnológicos y la globalización de la economía están pujando, en todo el mundo, por un modelo de capitalismo de mercado y de gobierno corporativo al estilo estadounidense ${ }^{45}$. Sin embargo, la correcta crítica a este sistema bursátil, es el enfoque a corto plazo del crecimiento de las utilidades y dividendos trimestrales contra una política corporativa alemana y japonesa orientada al largo plazo ${ }^{46}$.

Las tres teorías que a continuación explicaré son cardinales para el GCO, presentadas por la doctrina: (1) Mark ROE, (2) John COFFEE, y (3) Rafael LA PORTA, Florencio LOPEZ-DE-SILANES, Andrei SHLEIFER y Robert W. VISHNY (LLSV).

\section{A. Teoría Política}

El profesor de Harvard, Mark ROE, representa a la "teoría política" (political theory) de GC, para explicar porqué la tradición política-europea-continental de la "democracia social" (social democracies), elude la sepa- ración entre propiedad y control en una empresa ${ }^{47}$. Existe suficientes datos empíricos sobre el sistema de "control a través de la banca" de los mercados de capital, que viene perjudicando a las economías japonesa y alemana, al impedir el desarrollo de nuevos negocios ${ }^{48}$. ROE argumenta que en países con democracias sociales fuertes, tales como Alemania, Francia, Italia y Suecia, la política nacional presiona a las empresas a crecer para evitar bajas en la economía nacional; y así evitar interrumpir las buenas condiciones de empleo general. Los administradores renuncian a nuevas oportunidades comerciales y los accionistas a una mayor percepción de utilidades (maximización de beneficios), para poder mantener un bajo desempleo por política nacional; esto abre el debate y el problema entre los sueldos de los trabajadores y administradores, frente a los intereses de los accionistas ${ }^{49}$. En cambio, en los EE.UU., por su naturaleza de una política de libre mercado, incluyendo la política laboral que es apática en inmiscuirse en la administración de las corporaciones $^{50}$, pero a cambio ha implementado mecanismos que disciplinan a los administradores, y en particular una contabilidad transparente, fuertes incentivos en la remuneración de los administradores y directores, fusiones o tomas hostiles de control, y fuertes normas donde prima los intereses de los accionistas. Mientras que, los países civilistas mantienen dispositivos débiles de control; en tal ambiente, la concentración de capital se convierte en la debida reacción de defensa del capital por parte de los accionistas de control sobre los administradores. En los EE.UU. se constituyó un papel limitado al control por parte de los órganos gubernamentales a las instituciones financieras, efecto de la separación de la propiedad y control, pues dicha limitación al sistema financiero no era tan sólo el artefacto de carácter económico y político-populista, sino también el marco general de separación de poderes del sistema federal frente al sistema estatal ${ }^{51}$.

\section{B. Teoría de las Instituciones}

El profesor John COFFEE 52 de la Universidad de Columbia, argumenta que (a) el crecimiento de las Bolas de Valores y, (b) la ampliación correlativa de la dispersión de accionistas en las sociedades, son consecuencia directa del surgimiento del sector privado. Estos inversionistas privados en gran parte son libres de una directa interferencia o ingerencia gubernamental, y no por la presencia de determinadas protecciones a los inversores o por la preexistencia de normas-reglas legales o jurídicas. Mientras que la protección legal puede ser importante, tal protección puede no ser necesaria, hasta el punto en el que las Instituciones autorreguladoras pueden, con facilidad, desarrollar substitutos de garantía y salvaguardia; en el caso societario, salvaguardia de los accionistas. Dicho autor, al mismo tiempo opina que, el carácter descentralizado deL common law facilita la aparición de Instituciones privadas, en las que se incluyen normas particulares que imponen las bolsas de valores, y los mecanismos de la vinculación de inversión con la banca. Por otro lado, los sistemas civilistas tienden a poner a éstas Instituciones de control bajo el ineficiente control del Estado. 


\section{Teoría del Origen Legal}

LLSV declaran que el sistema jurídico anglosajón supera al sistema jurídico civil en la protección de los derechos de los accionistas minoritarios, ya que se da una aplicación más amplia de la hipótesis "law matters", o lo que es lo mismo, el reconocimiento de diferencias legales en diversos países -y que en muchos casos han sido transplantados de unos países a otros (porque la mayoría de leyes no son creadas desde cero)- de una de las cinco familias o tradiciones legales ${ }^{53}$. Es así que aparecen diferencias sistemáticas entre los distintos países que provienen de cada familia jurídica, en especial en la naturaleza de protección legal de los accionistas minoritarios y de los acreedores, relacionados con el origen de sus leyes corporativas y bursátiles ${ }^{54}$. En particular, los países del common law ostentan una mejor protección legal de los inversionistas que los países del civil law, particularmente los países franceses de tradición del Código Napoleónico55. Además cabe destacar, que en el mundo corporativo se subdivide hoy, en sistemas rivales de propiedad dispersada y concentrada, con diversas estructuras de gobierno corporativo con particularidades en cada uno de ellos ${ }^{56}$. Con ello, los países sajones proveen mejores derechos a los accionistas minoritarios, animando y generando así un mayor crecimiento del mercado de capitales, conllevando a una mayor dispersión de la propiedad accionaria ${ }^{57}$; clara evidencia de ello ha sido una-acción-un-voto.

Los cuatro economistas en mención (LLSV) ${ }^{58}$, explican que:

(i) Un sistema concentrado de propiedad (concentrated ownership system) con un modesto desempeño del mercado de capitales, se caracteriza por estar controlado por un accionista de control, por un débil gobierno bursátil, altas ventajas privadas de control, y bajos estándares de apertura y transparencia del acceso de información; pero con la posibilidad de existir un papel sustitutivo de supervisión desempeñado por la banca; $y$,

(ii) Un sistema disperso de propiedad (dispersed ownership system) se caracteriza por carecer de un único accionista de control, por poseer mercados bursátiles fuertes, estándares de accesos de información rigurosos y transparentes, donde el regulador bursátil constituye un importante mecanismo disciplinario y de control corporativo.

El estándar de protección legal parece depender de la naturaleza y de los orígenes de cada sistema legislativo de las naciones. Por lo tanto, LA PORTA et al. concluyen que, las diferencias en la estructura de la propiedad societaria están estrechamente correlacionadas con el impacto de las protecciones jurídicas otorgadas a los accionistas de minoría y minoritarios. Asimismo, "más del $70 \%$ de las diferencias (sistemáticas) sobre la valoración del voto de los accionistas, se explica por la calidad de la protección de los inversionistas que no-controlan la sociedad, determinado por las leyes de cada país, sus derechos existentes en caso de haber una transferencia de control, y el grado de la aplicación y cumplimiento de la ley"59.
La hipótesis que la "ley es relevante" (law matters) ${ }^{60}$ postula en lo esencial, que el desarrollo económico, particularmente en economías en transición, depende de la protección y de la aplicación de los derechos de los accionistas minoritarios ${ }^{61}$. Por el contrario, Bernard BLACK estima que ésta hipótesis de la importancia de las leyes corporativas es una cuestión trivial ${ }^{62}$, y Frank EASTERBROOK ha observado que las diferencias de gobierno corporativo a nivel internacional son atribuibles más a las diferencias en los mercados financieros que a las diferencias en la propia legislación ${ }^{63}$. Continuando con esta tendencia, catedráticos norteamericanos han reconocido que la Ley es solamente una imposición que regula el comportamiento. Otros académicos incluyen esta referencia a los mercados bursátiles, que están regulados a través de (a) mecanismos de determinación de precios y, (b) normas sociales, que gozan de aplicación debido a su poder de coerción y sanción ${ }^{64}$. Catedráticos, como los ya referidos en las anteriores Teorías Política e Institucional (BLACK, GILSON, COFFEE, EASTERBROOK, etc.), dudan que los impedimentos o las restricciones legales puedan servir como el pilar central de una teoría sobre la pasividad de los accionistas.

\section{Teorías de Gestión de las Sociedades}

En una sociedad anónima abierta, como consecuencia de la disociación entre propietarios -llámense accionistas, dueños o inversores- y quienes la administran, es ya una noción bien conocida. Este fundamento inició con la legendaria advertencia de Adam SMITH en la 'Riqueza de las Naciones' (The Wealth of Nations) sobre los inminentes problemas que resultarían del manejo de empresas de capital por quienes no fueren sus propietarios (diffuse stock ownership)65. Luego, el paradigma BERLEMEANS $^{66}$ (1932), redactado durante la profundidad de la gran depresión estadounidense (1929), reflexionó sobre los peligros y problemas surgidos por la dispersión de la propiedad entre los socios de una compañía y sus administradores. Esto es, el riesgo de que los recursos financieros invertidos -o capital social-, sean aprovechados en beneficio propio de los mandatarios o miembros del órgano social contra los intereses de los socios y acreedores. Todo ello tuvo un impacto inmediato y profundo en la legislación americana diseñada para proteger a los accionistas difusos o pequeños, que se verían enfrentados a los administradores. La base del paradigma BERLEMEANS sigue siendo, hasta hoy en día y en principio, la médula angular de la reglamentación bursátil en el mundo (p.e. CAC 40, DAX, FTSE, H. SENG, IBEX, NASDAQ, NIKKEI, NYSE, etc.). Empero, en la mayoría de sociedades bursátiles alrededor del globo, prevalece la presencia de un accionista de control ${ }^{67}$ (individual o familiar); por lo que el mencionado paradigma BERLEMEANS, sobre la difusión de la propiedad, no impacta de manera equiparable en el planeta ${ }^{68}$, a excepción de EE.UU. y UK ${ }^{69}$.

En conjunto a todo ello, en nuestro país no tenemos la noción clara de que debe primar: ¿Los intereses de los accionistas? ¿ ¿Los intereses de los administradores? Se- 
gún HANSMANN y KRAAKMAN, alrededor del planeta los sistemas de GC están convergiendo hacia el modelo corporativo orientado en los accionistas ${ }^{70}$, que ha sido el patrón dominante en UK y los EE.UU. desde el caso Revlon de $1986^{71}$. En la misma línea Roberta ROMANO, profesora de la Universidad de Yale, afirma que "los congresistas estadounidense tienden a adoptar legislación que maximizan la riqueza de los accionistas"72; y parte de la actual literatura sobre la materia asume que los mercados financieros están convergiendo hacia el modelo Norteamericano de "primacía del accionista"73. En el mismo sentido, el principal tribunal estadounidense en materia societaria, el Tribunal de Chancery (Delaware Court of Chancery), ha definido de modo afín que "los directores tienen la obligación de procurar, dentro del marco de la ley, maximizar de forma duradera los intereses de los accionistas [...]"74. A pesar de ocasionales discusiones académicas afirmando lo contrario, la norma sobre la maximización de los beneficios de los accionistas es norma incuestionable en los EE.UU.75. Sin embrago, nuestra jurisprudencia no se ha pronunciado al respecto, y esperemos que en caso de hacerlo, se inclinen por la primacía de los accionistas.

Dentro de las teorías sobre los gestores de la empresa, las principales son: A. La Teoría clásica del Mandato. B. La Teoría moderna del Órgano. C. La posición ecuatoriana.

\section{A. La Teoría clásica del Mandato}

Los cuerpos legales han enfocado el conflicto de la naturaleza jurídica de la relación que media entre los administradores y la compañía a través del mandato. Como antecedente a nuestro Código de Comercio, el "Art. 22 de la Ley francesa de 24-VII-1867, definía los administradores como mandatarios a plazo, revocables, asalariados o gratuitos, elegidos entre los socios. Pero la sentencia gala de 4-VI-1946, después de declarar que los órganos de la sociedad anónima 'están jerarquizados', concluye que la administración la ejerce el Directorio o Consejo elegido por la Junta, sin que ésta pueda arrogarse las prerrogativas de aquél"76. Paralelamente, nuestro Código Civil (Art. 2020; ex Art. 2047), define al mandato como "un contrato en que una persona confía la gestión de uno o más negocios a otra, que se hace cargo de ellos por cuenta y riesgo de la primera". El Código de Comercio, a su vez establece que el factor (gerente de una empresa, o establecimiento mercantil o fabril, o de un ramo de ellos) es quien administra por cuenta del dueño, y se confiere su cargo por la figura del mandato 77 .

\section{B. La Teoría del Órgano}

Aunque los administradores ejerzan su cargo por designación de la Asamblea General o de la Junta Directiva (Art. 231.1 de la $\mathrm{LC}^{78}$ ), ellos actúan por propia autoridad. El órgano de administración de la empresa es el receptor del deber de realizar y materializar la actividad económica que constituye el objeto social. Así como en la representación negocial voluntaria concurren dos voluntades: la del representante y la del representado. En la representación del administrador, en cambio, existe una sola voluntad, la voluntad del órgano; que es el instrumento mediante el cual se manifiesta la voluntad de la sociedad. La representación orgánica, constituye una secuela necesaria de la organización de la persona jurídica. Más que la manifestación de un derecho ajeno, es la expresión de un derecho propio del representante, anejo al cargo que ostenta ${ }^{79}$; porque según la teoría del órgano, los actos cometidos por los administradores en la esfera de sus atribuciones son actos de la compañía y no de las personas físicas que representan. La relación existente entre persona jurídica y órgano en general, es una relación denominada orgánica, para expresar que existe una compenetración entre persona jurídica y órgano (directorio), como la que hay entre representante y representado, cada uno de los cuales tiene su propia voluntad y libertad ${ }^{80}$. Esta teoría del órgano, se manifiesta por la actuación de dos elementos: primero, el carácter objetivo (la norma), y segundo el subjetivo (los directores), quienes están legitimados para actuar en virtud de la norma (Ley, estatuto social), y los propios deberes fiduciarios.

\section{La posición ecuatoriana}

Como vimos, nuestra legislación aparenta el seguimiento de la doctrina clásica del mandato, porque define con claridad a los administradores como mandatarios amovibles $^{81}$. A su vez, el Art. 255 de la LC impone a los administradores la misma responsabilidad que para los mandatarios. Empero, debe resaltarse que nuestra Ley de Sociedades, en parte, se separa de dicha teoría clásica, porque mientras que en el mandato civil y comercial el mandatario está obligado a proseguir con las instrucciones concretas del mandante (representación negocial), el poder de representar a la compañía supone una representación necesaria; puesto que en toda compañía debe existir un administrador para el cumplimiento de los objetivos sociales, tanto en la fase fundacional ${ }^{82}$ como en el curso de la sociedad in bonis ${ }^{83}$, no pudiendo funcionar sin éste cargo; algo que no ocurre en el mandato civil. Nuestra jurisprudencia se ha pronunciado al respecto, declarando que el director-gerente no tiene relación de dependencia sino de representación de la empresa, lo que es evidente si se toma en cuenta que tratándose de una persona jurídica, su forma de actuar es, forzosamente, a través de una tercera persona (representante legal); al respecto, el tratadista Luis Claro Solar, luego de exponer la Teoría de la Representación y la Teoría del Órgano, concluye que la persona jurídica no puede existir sin la cualidad de poder ser representada judicial o extrajudicialmente, cualidad que nuestro Código incluye como esencial en la definición de persona jurídica ${ }^{84}$.

El ligamen del administrador deriva de su condición de órgano, contrario a lo que ocurre en la sociedad de personas o comandita simple ${ }^{85}$, donde el administrador está ligado a ella por un vínculo asociativo al ser socio de la misma ${ }^{86}$. En la sociedad de capitales el administrador cumple una función especializada y técnica que le ha sido confiada, y por ello perciben una remuneración ${ }^{87}$; 
mientras que, en las sociedades personalistas los administradores, salvo pacto en contrario, no obtienen compensación. Paralelamente, en sociedades supercapitalizadas, la confianza personal con los gestores se disipa o desvanece, al no existir una unión de lazos personales o familiaridad con los accionistas-capitalistas, que suelen permanecer en el anonimato hasta la celebración de la Junta. Conjuntamente, el Art. 252 de la LC declara que "[...] si la representación recayere sobre un organismo social, éste actuará por medio de un presidente"; siendo aquí, cuando la diligencia del mandatario es sustituida por la actuación orgánica. Sin olvidar que algunas reglas del mandato son supletorias cuando sea necesario. De igual manera, por ejemplo en España, la teoría del mandatarioadministrador se considera hoy en día superada ${ }^{88}$.

\section{Los problemas de Gobierno Corporativo en la actual legislación ecuatoriana}

En gran medida, los CGC nacen por la falta de transparencia en el manejo del patrimonio de las empresas, los débiles controles externos (auditores externos, $\mathrm{CNV}$, Superintendencias, etc.) e internos (Junta General de Accionistas, comisarios, socios, etc.); en este trabajo, nos enfocaremos en los controladores internos.

Por clasificación normativa existen tres niveles de protección: (1) la Ley; (2) la Autorregulación; y, (3) Cumplir o informar:

1. Ley.- Este es el nivel más fuerte de cumplimiento, por cuanto la legislación ostenta carácter general (leyes, decretos, reglamentos, resoluciones), y es obligatoria a todas las sociedades y sus administradores. En nuestro país podemos subdividir en leyes aplicables a las sociedades, y leyes aplicables a las compañías que negocian en Bolsa.

2. Autorregulación.- La autorregulación es la asunción voluntaria por parte de las empresas, por lo general las sociedades cotizadas, que reforman sus estatutos sociales para adecuar sus conductas a las normas recomendadas por las autoridades o grupos empresariales. A éste rango pertenece el CEc.

3. Cumplir o informar (comply or disclose).- En vez de que las empresas busquen evadir o esquivar algunas reglamentaciones, y se prefiera la veraz información para los inversores, cabe la posibilidad en ciertos casos de cumplir con las regulaciones bursátiles o informar al público los motivos por los que se ha preferido no seguir un determinado lineamiento ${ }^{89}$. Ésta es una normativa intermedia entre la Ley y la autorregulación.

Debemos resaltar que dentro de los entes externos, los auditores de cuentas ${ }^{90}$ están obligados a fiscalizar los estados financieros, puesto que las sociedades bursátiles son compelidas a contar con el informe de dichos auditores $^{91}$. Los auditores externos aplican las Normas Ecuatorianas de Auditoría (NEA), pero ésta normativa no posee los estándares mínimos exigidos por las "normas in- ternacionales de auditoría"92. A su vez, los dos órganos gubernamentales de vigilancia de sociedades bursátiles son: (1) la Superintendencia de Bancos y Seguros ${ }^{93}$; y, (2) el Consejo Nacional de Valores ${ }^{94}$. Si bien dichas instituciones ejecutan una buena labor, los requerimientos mínimos de información por parte de las sociedades bursátiles ecuatorianas al público aún son débiles respecto de otros países ${ }^{95}$. Por otra parte, dentro de los entes internos tenemos a los accionistas, a la Junta General, los administradores, el directorio (organismos directivos de la compañía), y los comisarios; subsidiariamente están los acreedores sociales.

\section{Los Accionistas}

En la actual legislación, el marco general de derechos de los accionistas lo concede la acción (valor o título valor). La acción confiere a su titular legítimo la calidad de accionista y le atribuye, como mínimo, los derechos fundamentales que de ella se derivan y se establecen en la LC (Art. 178). El Art. 207.1 adjudica a su titular legítimo la condición de socio confiriéndole los derechos -más no obligaciones- reconocidos en la Ley y en los Estatutos ${ }^{96}$. La única excepción legal, es el requerimiento de todo accionista de realizar el pago del importe de la porción del capital, que le corresponde desembolsar (Art. 218) ${ }^{97}$. La acción como conjunto de derechos integrantes de la condición de accionista, bajo la catalogación por el contenido98 en las sociedades bursátiles se dividen en: (1) derechos patrimoniales o económicos (Alemania: wert, vermogen, eigennutzlicherechte; EE.UU y UK: patrimonial rights), y en (2) derechos administrativos o políticos (Alemania: herrschafts, mitterwaltungs, gemeinnutzliche rechte; EE.UU. y UK: political rights).

Los derechos económicos son aquellos que, como su nombre lo indican, poseen un carácter dinerario por el propio fin de lucro de las sociedades mercantiles; aún cuando existen hoy en día determinadas excepciones. A su vez esta es una diferencia relevante frente a las sociedades personalistas, puesto que las compañías de capital constituyen en esencia- siempre un organismo económico. Dentro de los derechos patrimoniales, los socios gozan de:

1. El derecho a participar en el reparto de las ganancias sociales, en caso de existirlos (Arts. 207.2 y 208).

2. El dividendo acordado en la Junta General es una deuda de dinero (Art. 209).

3. El derecho a participar en el patrimonio resultante de la liquidación (Art. 207.2).

En cambio, los derechos políticos permiten a los accionistas su participación directa en la vida de la sociedad, en especial facultan su asistencia, intervención y sufragio en las Juntas, obtención de información de los aspectos corporativos y los libros contables-financieros, entre los más significativos. Algunos de los derechos políticos son:

1. Asistir, intervenir en las juntas generales y votar cuando sus acciones le concedan el derecho a voto (Art. 207.4).

2. Integrar los órganos de administración o de fiscalización de la compañía (Art. 207.5). 
3. Tener preferencia para la suscripción de acciones (Art. 207.6).

4. Examinar los libros y documentos de la compañía relativos a la administración social (Arts. 15 y 248).

5. Denunciar irregularidades a los Comisarios (Art. 214).

6. Impugnar las resoluciones de la Junta General y demás organismos de la compañía, con el $25 \%$ del capital (Arts. 207.7 y 249).

No olvidemos que el primer fin de los inversionistas en sociedades supercapitalizadas es el reparto de dividendos y el incremento del precio de mercado de las acciones. Tanto los dividendos ordinarios y los extraordinarios son rendimientos procedentes del capital mobiliario, o retribuciones a los partícipes del capital social. El Tribunal Supremo Español estima que las acciones ordinarias confieren a su titular el derecho a percibir dividendos, que es un derecho concreto que posee cada socio sobre su cuota de beneficio repartible tras el acuerdo decidido por la Junta ${ }^{99}$, comenzando su exigibilidad, bien a partir de ese momento o, transcurrido el plazo que la Junta de Accionistas señale al órgano de administración para poner al cobro los dividendos acordados. En el reparto de dividendos hay que distinguir el derecho abstracto del mismo, que es indiscutible, y el derecho concreto, que se obtiene sólo desde que hay un acuerdo de la Junta General. El tránsito del derecho abstracto al concreto corresponde por votación a la Junta General, órgano soberano de formación de la voluntad general. Por citar un informe, el McKinsey Global Investor Opinion Survey demostró que el $15 \%$ de los inversionistas institucionales, estiman al GC más importante que los estados financieros de las empresas; y el $22 \%$ de estos inversores está dispuesto a pagar un $19 \%$ más por el valor de las acciones. Esto refleja, que los inversores sí pagan por mejoras en el GC de las compañías 100 .

Los accionistas son los propietarios de la sociedad en mayor o en menor medida, puesto que la S.A. de capital está formada por la aportación de los accionistas que responden únicamente por el monto de sus acciones (Art. 143 de la LC). Podemos clasificar a los accionistas por el poder que poseen en la compañía, que además refleja ciertos derechos para supervisar la gestión de la sociedad: a) Accionistas de control (ADC); b) Accionistas de minoría; y, c) Accionistas minoritarios.

Los primeros, los ADC o accionistas titulares de partes significativas, ostentan -en la praxis- frente a los otros accionistas, y por reconocerse el derecho de la mayoría, entre otros derechos:

a) La facultad de nombrar y separar a los administradores y miembros del Directorio en cualquier momento (Art. 231 de la LC);

b) Modificar los Estatutos sociales;

c) Declarar el reparto de los beneficios o utilidades;

d) Determinar las reservas voluntarias;

e) Negar o bloquear peticiones de la minoría;

f) Nombrar a los comisarios; (etc.)

Ecuador no tiene una definición de ADC, sin embargo se puede desprender del Art. 36 de la LMV101 y del derecho comparado un concepto de control. De estas normas, se entiende que existe control, cuando un individuo o sociedad posee y ejerce la supremacía o dominio de una sociedad en alguno de los casos siguientes:

(a) Posee la mayoría de los derechos de voto, directamente $o$ indirectamente por acuerdos con otros accionistas; 0 ,

(b) Posee el poder para nombrar o destituir a la mayoría de los miembros del Consejo u órgano de administración.

Complementariamente, en derecho comparado, por ejemplo la Directiva 2003/6/CE del Parlamento Europeo y del Consejo (28-I-2003), dispone en su primer artículo que existe control cuando "la actuación de una persona o de varias concertadamente para asegurarse una posición dominante sobre la oferta o demanda de un instrumento financiero con el resultado de fijación, de forma directa o indirecta, de precios de compra o de venta o de otras condiciones de transacción no equitativas". A su vez, la Sociedad Europea (SE) en su considerando decimoquinto declara que, "los derechos y las obligaciones relativos a la protección de los accionistas minoritarios y de terceros que incumben a una empresa por el hecho de ejercer un control sobre otra empresa sometida a una legislación diferente están regulados, en virtud de las normas y los principios generales del Derecho internacional privado, por el ordenamiento jurídico al que esté sometida la empresa controlada"102.

Por su parte, los denominados accionistas de minoría - llamados derechos de minoría cualificada ${ }^{103}$, se incluyen en el tema más amplio de la tutela de la minoría en la sociedad anónima, intentando reducir y limitar el abuso de poder del ADC (que lo anglosajones denominan fraud on minority). La tutela de la minoría, en sentido estricto, son aquellos derechos o facultades concedidos al socio o socios que alcanzan una determinada participación en el capital o por factor numérico; o en palabras de la doctrina alemana, "derechos de minoría en sentido técnico"104. Esta minoría tiene derecho, en lo principal:

a) El derecho de información sobre lo que está ocurriendo en la sociedad (Arts. 15 y 248 de la LC; Arts. 13, $14,17,18,19,24$ y ss. de la LMV), y sin que pueda ser negada por el presidente de la Junta con el $25 \%$ del capital ${ }^{105}$ (Art. 248 de la LC);

b) Denunciar a la JG fundadas sospechas por actitud negligente de los comisarios, con el 20\% (Art. 284);

c) Solicitar a la Superintendencia de Compañías que designe un perito para la comprobación de la verdad del balance y demás documentos presentados por el administrador, con por lo menos el 20\% (Art. 299).

d) Pedir la convocatoria a JG extraordinaria, cuando la solicite al menos el 25\% capital social (Art. 213).

e) Prorrogar la celebración de la Junta con el $25 \%$ del capital;

f) Apelar las decisiones de la mayoría ante la Corte Superior, con por lo menos el $25 \%$ del capital (Arts. 249 y 250).

g) Oponerse a transigir o renunciar al ejercicio de la acción social de responsabilidad (ASR) o acción de responsabilidad contra los administradores, con el apoyo del $10 \%$ de los socios (Art. 272);

h) Solicitar a la Superintendencia de Compañías que nombre al interventor, con por lo menos $10 \%$ del capital (Art. 354); 
En cambio, los accionistas minoritarios (socios más dispersados) tienen en la praxis derechos muy limitados, aunque pueden asociarse o agruparse, denominado este derecho de agrupación de acciones, para llegar a conformarse en minoría e incluso convertirse en ADC. En lo más relevante, la Ley otorga a los accionistas minoritarios:

a) El derecho de información sobre lo que está ocurriendo en la sociedad (Arts. 15 y 248 de la LC; Arts. $13,14,17,18,19,24$ y ss. de la LMV); y solicitar información y aclaraciones del las cuentas anuales y del informe de auditoria;

b) La calidad de socio (Arts. 178 y 207.1);

c) Negociar libremente las acciones (Art. 207.8).

d) Participar en los beneficios sociales, debiendo observarse igualdad de tratamiento para los accionistas de la misma clase (Art. 207.2);

e) El derecho a asistir y a votar en las Juntas Generales (Art. 207.4);

f) El derecho a pedir la convocatoria judicial de la Junta (Art. 212);

g) El derecho de agrupación de acciones;

h) El derecho a hacerse representar;

i) Integrar los órganos de administración o de fiscalización de la compañía si fueren elegidos en la forma prescrita por la ley y los estatutos (Art. 207.5);

j) Gozar de preferencia para la suscripción de acciones en el caso de aumento de capital (Art. 207.6);

k) El derecho a mantener su participación en la sociedad en caso de transformación o fusión (Art. 334);

l) En caso de oponerse o estar disconformes con transformación, fusión o escisión, tienen derecho de separarse de la compañía (Art. 332);

m) El derecho a pedir la convocatoria de la Junta General, cuando se estime que existe causa legitima de disolución de la sociedad (Art. 359);

n) El derecho de separación en los supuestos de sustitución del objeto, de transformación de sociedad anónima en sociedad colectiva o comanditaria, y de transferencia del domicilio social al extranjero (Art. 332 y ss).

o) Participar en la distribución del acervo social, en caso de liquidación de la compañía (Art. 207.3);

p) Impugnar las resoluciones de la junta general y demás organismos de la compañía en los casos y en la forma establecida en los Arts. $215 \mathrm{y}$, no podrá ejercer este derecho el accionista que estuviere en mora en el pago de sus aportes (Art. 207.7).

De la enumeración descrita, aparentan ser muchos los derechos de los accionistas minoritarios; aunque, en lo principal, existen dos problemas. Primero, el legislador no ha regulado los medios para controlar los posibles abusos por parte de los accionistas de minoría. Así, junto al peligro de abuso de la mayoría, que suele preocupar a la doctrina, es posible plantearse el riesgo del abuso de la minoría; probablemente ello se deba a la muy escasa utilización de estos derechos, sobre todo en las grandes sociedades abiertas donde su ejercicio resulta extremadamente difícil ${ }^{106}$. Segundo, la dificultad que existe para ejercer en realidad todos los derechos de accionistas. Se desprende que la intención de algunos de derechos de minoría, es multiplicar los supuestos de posibles conflictos entre la mayoría y la minoría, para lograr una superior judicialización de la vida social-empresarial, aunque en nuestro sistema normativo sigue siendo efímera ésta judicialización para el caso de sociedades bursátiles, por los fuertes impedimentos para poder demandar a los administradores, y no hablemos si quiera de los ADC. Como veremos, el impedimento más grande es la carencia de adecuados mecanismos disponibles a los accionistas minoritarios para supervisar la gestión de los administradores, directores y comisarios.

Los administradores no se encuentran inmunes por los actos y omisiones que en el ejercicio de su cargo hayan cometido o dejado de cometer (Art. 255). Para ello, la normativa establece un procedimiento especial, por el cual, la sociedad puede demandar a sus directivos, gerentes y consejeros. Ésta acción, en Ecuador, está determinada en el Art. 215 de la LC y conceptuada como Acción Social de Responsabilidad (ASR). En otros países existe el mismo proceso, como por ejemplo: Albania, Argentina, Australia, Austria, Hong-Kong, Vietnam ${ }^{107}$, etc.

El Art. 264 impone la responsabilidad de los administradores en el ámbito general de "triple requisito clásico de la teoría civil de la responsabilidad por daño, entre los cuales se integra el de la culpa"108. La responsabilidad por culpa está sujeta a la teoría general del ilícito civil, y sin excepción de ningún tipo respecto del grado de culpabilidad exigible ${ }^{109}$. En nuestro ordenamiento mercantil, la temática sobre el problema de la responsabilidad de los administradores de las sociedades, ha venido manteniendo una postura benevolente, consistente en no imputarles responsabilidad por toda posible falta de diligencia, sino exclusivamente por culpa lata o levis in abstracto (dolo o negligencia grave). Hoy se aplica la exigencia para los administradores de la sociedad anónima un nivel de diligencia más elevado y específico que el del bonus paterfamilias, o negligencia ordinaria. En el sistema civilista comparado, algunos tratadistas como Eduardo POLO, en la actualidad subrayan que una vez suprimida la exigencia de la negligencia grave para la imputación de responsabilidad a los administradores que ahora responderá por las llamadas faltas de gestión. De la propia dicción del Art. 133 de la Ley de Sociedades Anónima española (LSA), la diligencia exigible al administrador de un ordenado empresario y representante leal se refiere a una diligencia específica (no a una diligencia ordinaria) con la que se debe desempeñar el cargo de administrador. La LSA no requiere ningún tipo de capacitación o entrenamiento para ser administrador (cargo de gestión) o empresario, aunque su profesionalidad debe ser entendida asimismo como competencia profesional, que ha de exigirse indudablemente en función de la capacitación técnica y profesional de los administradores o del consejo en su conjunto, se encuentra implícita en la apelación al ordenado empresario como criterio para medir la diligencia exigible al administrador, aplicable al mismo nivel de atención, prudencia, dedicación y competencia que se predican del empresario ordenado; cualidades precisas pretendidas para aquellos que se dediquen al mismo género de comercio que la sociedad ${ }^{110}$. Los administradores responderán no sólo por el daño derivado en relación de 
causa a efecto de un comportamiento malicioso, abusivo o gravemente negligente ${ }^{111}$. Aunque es necesario demostrar que la exigencia para la efectividad de la responsabilidad extracontractual o aquiliana, requiere de los siguientes elementos: a) una acción u omisión ilícitas, con la consiguiente situación de culpabilidad; b) la producción de un daño o daño efectivo; $y, c$ ) un nexo causal entre la acción u omisión culpable y el daño producido o la existencia de causalidad suficiente ${ }^{112}$.

Sólo la Junta puede remover a los administradores y más miembros de los organismos de administración, aún cuando el asunto no figure en el orden del día (Arts. 234 y 270). Queda claro, que es la Junta General es la única que puede destituir a los administradores-directores y en cualquier momento por mayoría simple (siempre que los estatutos no impongan un porcentaje superior).

Las dificultades más grandes en nuestro sistema para aplicar la ASR son:

a) Poseer o representar al menos $25 \%$ del capital pagado

(Art. 215): que en sociedades supercapitalizadas es elevada en exceso, y apenas suelen mantener éste porcentaje los bloques de control. En cambio en otros países, y por citar el caso francés ${ }^{113}$ en el cual existe proporcionalidad entre el valor de la sociedad y el porcentaje mínimo requerido para iniciar una ASR, hasta mantener un mínimo un $1 \%$ del capital social. Incluso, lo más aconsejable sería iniciar la ASR contra los administradores o los accionistas, con una (1) sola acción, como acontece en Australia, Barbados, EE.UU., entre otros.

b) Depósito de acciones: significa que no puede el demandante transferirlas o enajenarlas hasta la culminación del proceso, lo cual provoca que un socio quede congelado (freeze-in) con las acciones-valores empresa, hasta que la Corte resuelva la contienda legal materia del juicio.

c) Carga de la prueba del actor: el demandante tiene la carga probatoria sobre lo alegado ${ }^{114}$, o lo que es lo mismo, la carga de la prueba a cargo del accionistaactor bajo la locución iudex iudicet secundum allegata et probata partium 115 .

d) El ADC puede transigir la responsabilidad de los administradores: esto puedo ocurrir antes de la aprobación de su responsabilidad en la Junta General, como después de haber sido aprobada en ella (Art. 272116); en el segundo caso, condicionando la oposición de al menos el $10 \%$ de los socios. Además, el ADC en ningún momento está limitado de ejercer el voto en la Asamblea General, aún cuando mantenga un conflicto de interés entre el gestor y la sociedad. Juntamente, el Art. 265.3 expone que la responsabilidad de los administradores frente a la compañía quedará extinguida por aprobación de la gestión, o por renuncia expresa a la acción, o por transacción acordada por la Junta.

e) Aún si la minoría prevalece en la ASR y el administrador es removido de su cargo (Art. 272), nada imposibilita a que el $\mathrm{ADC}$ de volver a nombrar al mismo administrador.

f) Inclusive, la responsabilidad de los administradores frente a la compañía quedará extinguida cuando ellos hagan constar su inconformidad a los comisarios, en el plazo de 10 días, si estuviesen exentos de culpa (Art. 264).

g) No son testigos idóneos los socios entre si por falta de imparcialidad: "insólito" pero cierto, "el socio por su coasociado o por la sociedad" (Art. 216.11; ex Art. $220.11 \mathrm{del} \mathrm{CPC}$ ); menguando en muchos casos la declaración y participación de los otros socios contra el ADC o contra el socio-administrador. Se podría hablar, en sentido estricto, que esta norma se restringe sólo a las sociedades en comandita y compañía limitada, al referirse al "socio" y no al "accionista" que aplica a las sociedades anónimas, pero en no hay jurisprudencia que ratifique esta tesis; y la "sociedad" se emplea a todas las empresas descritas en la LC.

h) No puede el accionista apelar de las resoluciones que establezcan la responsabilidad de los administradores o comisarios en una ASR (Art. 249): sólo pueden recurrir de la sentencia los propios demandados, generando indefensión a los accionistas minoritarios y a la propia sociedad, al impedírseles apelar la decisión del primer Tribunal. El Art. 250 declara que "de la sentencia de la Corte Superior podrá interponerse el recurso de casación ante la Corte Suprema de Justicia"; pero en ningún momento está claro si la presentación del recurso extraordinario lo puede interponer sólo el administrador-demandado, o si también lo puede hacer el demandante. Siguiendo el Art. 216 para la impugnación de los acuerdos sociales, expone que "de la sentencia pronunciada por la Corte Superior podrá interponerse el recurso de casación ante la Corte Suprema de Justicia"; por analogía, también se aplica este supuesto para la ASR.

i) Las acciones concedidas en se sustanciará en juicio verbal sumario (Arts. 216 y 249).

j) Al menos en el Ecuador, la transferencia de acciones no son bloqueadas antes de la Asamblea, o es indispensable su deposito varios días antes de su celebración.

Similarmente, los actos de la sociedad, ya sean de la Junta General o del directorio, pueden ser objetados por los accionistas. La impugnación de los acuerdos sociales permite a cualquier accionista una fiscalización jurisdiccional de las decisiones tomadas por los órganos sociales, que han tomado sus decisiones por mayoría, para poder así formar la voluntad social. La voluntad social se impone a todos los accionistas, pero sólo si la Junta ha actuado dentro de sus competencias y respetando los límites impuestos por la Ley, los estatutos y el interés social; si los acuerdos no respetan cualquiera de estos límites, el accionista podrá impugnar los actos sociales ${ }^{117}$. El Art. 215 requiere para poder gozar de legitimación activa, representar por lo menos $25 \%$ del capital social, y se ejercitará este derecho de igual modo que la ASR dispuesta en el Art. 249.

Los problemas para aplicar la impugnación de los actos sociales, en relación con los ya descritos en la ASR, son:

a) Poseer o representar al menos $25 \%$ del capital pagado

(Arts. 215 y 249): se exige este elevado porcentaje.

En otros países, España por ejemplo, requiere que los socios posean tan solo 1 acción ${ }^{118}$. 
b) Depósito de acciones; Carga de la prueba del actor; El ADC puede transigir la responsabilidad de los administradores; No son testigos idóneos por falta de imparcialidad; No puede el accionista apelar de las resoluciones que establezcan la responsabilidad de los administradores o comisarios; Este proceso se sustanciará en juicio verbal sumario; vid supra.

c) Para la impugnación es requisito presentar la demanda dentro del plazo (no término) de 30 días, a partir de la fecha del acuerdo o resolución; tiempo que es a nuestro parecer corto.

En nuestro país, los accionistas careen de dos procesos esenciales para proteger a la sociedad y sus propios derechos: estos son el "proceso derivado" o derivative suit, y la "acción de clase o de grupo" o class action suit"19. El primero, el derivative suit ${ }^{120}$ busca que el accionista demande en nombre de la compañía por daños causados a ésta, ya que defiende sus propios intereses de manera indirecta; y para iniciar esta acción, no se requiere aprobación de la Junta de Socios. Este mecanismo permite que cualquier socio demande a los administradores por dolo o negligencia en su gestión, procurando mayor beneficio general de la empresa. El segundo, en el class action ${ }^{121}$ para los asuntos mercantiles y societarios, un solo demandante estaría facultado para representar a todos los accionistas (minoritarios) que pueden verse perjudicados por una misma causa o motivo. En Ecuador, sólo cabe la acumulación de acciones o acumulación de procesos, pero implica que cada accionista perjudicado se presente como co-peticionario (Art. 71; ex Art. 75 del CPC).

Por todo lo expresado, es inminente la posibilidad que los accionistas supervisen la administración de las sociedades, a través de la judicialización de las decisiones corporativas. Recordando que en última medida, el poder judicial tiene la competencia de examinar y resolver sobre las resoluciones y decisiones de los dos órganos gubernamentales, la Superintendencia de Compañías y el CNV122, a más de la Junta General (Art. 249).

\section{La Junta General}

La Junta General de Accionistas o Asamblea General de Socios es el máximo órgano de la compañía, cuando es legalmente convocada (Art. 230), y ellas pueden ser ordinarias, extraordinarias o universales (Art. 233 y ss.). La Asamblea General tiene la facultad y poderes para resolver, por mayoría, todos los asuntos relativos a los negocios sociales, y para tomar las decisiones que juzgue convenientes en defensa de la empresa ${ }^{123}$.

Nuestra legislación no está adecuada para limitar el voto de los bloques de control, en los supuestos de conflicto de intereses entre la sociedad y dichos accionistas de control (ADC) ${ }^{124}$; otros países como España ${ }^{125}$, Egipto ${ }^{126}$, Finlandia ${ }^{127}$ y Japón ${ }^{128}$ siguen el mismo sistema. En cambio, disímil es lo que ocurre por ejemplo en Singapur ${ }^{129}$, donde los accionistas minoritarios y los ADC están impedidos de votar cuando tengan ellos una posible disyuntiva con la sociedad. En EE.UU., en cambio, cuando exista conflicto de intereses por un acuerdo votado en JG o entre partes relacionadas, está obligado el ADC be- neficiado, de probar él, que el acuerdo fue ejecutado en el mejor interés de la corporación ${ }^{130}$. En Nueva Zelanda es requisito el informe de un perito independiente anterior a la aprobación bajo estos supuestos ${ }^{131}$. Y en UK, el ADC no debe ejercer sus derechos de voto de manera que discrimine a la minoría para expropiarles sus derechos de propiedad ${ }^{132}$.

Otro elemento interesante en nuestro Derecho, es la falta del voto a distancia ${ }^{133}$ o proxy voting, en el cual los accionistas que no acuden en persona a la Junta General, pueden ejercer su derecho de voto por diferentes medios, como son p.e. el correo postal, el fax o el correo electrónico. Incluso, debe prohibirse que los votos en blanco o las delegaciones de voto en blanco, a favor de miembros del Directorio o de las fondos de inversión.

\section{Los Administradores}

Aunque la Junta General es el órgano supremo de la empresa, la gran parte de las decisiones es delegada al Directorio y a los administradores, por el inconveniente que significaría el tener convocado a todos los accionistas para cada decisión a resolverse por ella. Por eso, es preciso que la administración de una corporación esté encomendada a una o un pequeño grupo de personas. De ahí tenemos a dos órganos de distinta jerarquía, la Junta y los administradores, que actúan por separado. En nuestro país no es obligatoria la existencia de un Directorio para las sociedades abiertas, por lo que su creación y funcionamiento está especificada en los Estatutos. Lo que la LC exige, es que en el contrato social aparezca con claridad quién o quiénes tienen la representación judicial y extrajudicial, y si la representación recayere sobre un organismo social, éste actuará por medio de un presidente (Art. 252). Los directores o consejeros están sujetos a los mismos deberes y obligaciones que cualquier administrador. Para garantizar la correcta actuación de los consejeros y los administradores, la normativa establece que ellos son responsables de sus actos u omisiones en el ejercicio de sus funciones.

Los administradores (gerente, gerente general, presidente, etc.) y los directores miembros del consejo de administración ${ }^{134}$ tienen dos deberes esenciales. Estos son el deber de diligencia y el deber de lealtad, interpretados por la jurisprudencia comparada como la conducta de un ordenado comerciante-empresario y de un representante leal ${ }^{135}$. Estos dos deberes son los deberes fiduciarios, que afectan de manera directa en la actividad y en el comportamiento de los administradores. Correspondientemente, la especialización funcional consiste en atribuir la función de administrar en sentido amplio la empresa a cualquier persona, ya sea física o jurídica, con independencia de que ostente simultáneamente o no la condición de accionista; no existiendo una clara delimitación de competencias entre la Junta General y los administradores ${ }^{136}$. En resumen, los deberes fiduciarios son los vínculos de confianza derivados de la clásica doctrina de la fiduciary duty que impone a los gestores una actuación directa frente a los socios de buena fe y $\sin$ fraude ${ }^{137}$. 
El ordenado empresario busca el buen desempeño y la carencia de negligencia en la actividad de los administradores, y un representante leal es la protección de posibles conflictos de intereses entre la sociedad y sus encargados; siendo estos deberes el paradigma y correlato del buen padre de familia ${ }^{138}$. Este deber de ordenado empresario, que nuestra Ley de Compañías habla de una "gestión con la diligencia que exige una administración mercantil ordinaria y prudente" (Art. 262), permite una elástica aplicación a las exigencias específicas de la actividad desarrollada por cada sociedad singularmente considerada, donde los administradores no pueden ejecutar operaciones ajenas al objeto social; ya que hacerlo significa violación de las obligaciones de administración y del mandato que tuvieren (Art. 261).

En cambio, el deber del representante leal advierte una medida de competencia profesional presunta que exige la observación y cuidado primordial de los intereses del administrador, aunque no está expresado en nuestra LC. Por ejemplo, el reformado Art. 127 ter de la LSA española define el deber de lealtad como:

1. Los administradores no podrán utilizar el nombre de la sociedad ni invocar su condición de administradores de la misma para la realización de operaciones por cuenta propia o de personas a ellos vinculadas. [...]

2. Ningún administrador podrá realizar, en beneficio propio o de personas a él vinculadas, inversiones o cualesquiera operaciones ligadas a los bienes de la sociedad, de las que haya tenido conocimiento con ocasión del ejercicio del cargo, cuando la inversión o la operación hubiera sido ofrecida a la sociedad o la sociedad tuviera interés en ella, siempre que la sociedad no haya desestimado dicha inversión u operación sin mediar influencia del administrador.

3. Los administradores deberán comunicar al consejo de administración cualquier situación de conflicto, directo o indirecto, que pudieran tener, con el interés de la sociedad. En caso de conflicto, el administrador afectado se abstendrá de intervenir en la operación a que el conflicto se refiera. En todo caso, las situaciones de conflicto de intereses en que se encuentren los administradores de la sociedad serán objeto de información en el informe anual de gobierno corporativo.

4. Los administradores deberán comunicar la participación que tuvieran en el capital de una sociedad con el mismo, análogo o complementario género de actividad al que constituya el objeto social, así como los cargos o las funciones que en ella ejerzan, así como la realización por cuenta propia o ajena, del mismo, análogo o complementario género de actividad del que constituya el objeto social. Dicha información se incluirá en la memoria.

Apenas el Art. 135 del CCom, "prohíbe a los factores y dependientes traficar por su cuenta y tomar interés, en nombre propio o ajeno, en negociaciones del mismo género que las del establecimiento en que sirven, a menos que fueren expresamente autorizados para ello. En caso de contravención se aplicarán al principal las utilidades que produzcan las negociaciones, quedando las pérdidas por cuenta de aquellos". Empero, es una interpretación extensiva de la Ley mercantil, y más importante aún, no tenemos jurisprudencia que recalque en nuestro ordenamiento jurídico ésta posibilidad. Por ello, entendemos que en realidad no existe en nuestra legislación de un verdadero deber de lealtad.

A su vez, los administradores están prohibidos de negociar o contratar por cuenta propia, directa o indirectamente, con la compañía que administren (Art. 261), y conforme al Art. 243, los "miembros de los organismos administrativos y de fiscalización y los administradores no pueden votar: 1. En la aprobación de los balances; 2. En las deliberaciones respecto a su responsabilidad; y, 3 . En las operaciones en las que tengan intereses opuestos a los de la compañía". Aunque, "en caso de contravenirse a esta disposición, la resolución será nula [sólo] cuando sin el voto de los funcionarios precitados no se habría logrado la mayoría requerida".

\section{Los Comisarios}

Los comisarios, socios o no, nombrados por la Junta General o en el contrato de constitución de la compañía (Art. 274). Ellos gozan del derecho ilimitado de inspección y vigilancia sobre todas las operaciones sociales, sin dependencia de la administración y en interés de la compañía. Además, los comisarios serán temporales y amovibles. Los primordiales y deberes de los comisarios son:

1. Emitir un informe anual de su gestión (Art. 15).

2. Tienen el deber de acudir a las Juntas Generales, aunque su inasistencia no será causal de diferimiento de la reunión (Art. 242).

3. Disfrutan de la facultad de convocar a Junta General (extraordinaria) con el carácter de urgente, y su reunión no podrá ser diferida (Arts. 236 y 248).

4. Deben convocar a la Junta General a cuando falte el administrador, y el estatuto no prevea la forma de sustituirle (Art. 266).

5. No pueden representar a otros accionistas (Art. 211).

6. Deben recibir la memoria razonada acerca de la situación de la compañía por parte de los administradores (Art. 263.4).

7. Están obligados a informar oportunamente a la Superintendencia de Compañías sobre las observaciones que formulare y les fueren notificadas (Art. 288).

Positivo es que los comisarios no puedan delegar el ejercicio de su cargo; $y$, que tampoco puedan representar a los accionistas en la Junta General (Art. 280.2 y 280.3). Aunque el Art. 280.1 prohíbe a los comisarios a "formar parte de los órganos de administración de la compañía"; lo que en de verdad debería decir es que tienen prohibida la votación en las resoluciones, mas no su asistencia. Los comisarios en la actual legislación padecen de cuatro problemas esenciales:

a) Los comisarios no asisten a las reuniones de Directorio; y en la praxis, no están en realidad al tanto de todo lo que ocurre en la empresa. 
b) Los términos de inhabilidad e independencia para ser comisario, respecto de los miembros del Directorio son limitados (Art. 275).

c) Falta de independencia con los ADC, a menos de que estos sean su cónyuge o familiares (Art. 275.3).

d) Los accionistas minoritarios no pueden nombrar a uno de los comisarios.

Por otra parte, los comisarios podrían ser el contrapeso de los administradores e incluso de los ADC; parecido a lo que ocurre con la comisión o comité de auditoría estadounidense (audit committee) ${ }^{139}$, donde éste comité elige, evalúa, nombra y reemplaza a los auditores externos, y fiscaliza la labor del Directorio. Indispensable a su vez que todos sus miembros son independientes de la administración. De igual manera, la medida 40 del CAGC estima que debe conformarse comisiones para ejercer ciertas funciones, siendo las más frecuentes la Comisión de Auditoría y la Comisión de Nombramientos y Remuneraciones y, en función de las características del negocio; y estas comisiones estén conformadas por miembros exter$\operatorname{nos}^{140}$. No obstante en la actualidad, las compañías pueden designar para su fiscalización y control consejos de vigilancia o de inspección, en cuyo caso se extenderán a éstos las disposiciones que establecen los derechos, obligaciones y responsabilidades de los comisarios (Art. 287). Incluso, los comisarios podrían tener la labor de recomendar la elección y retribución a los directivos (nominating committee ${ }^{141}$ ).

\section{Los Acreedores}

Los acreedores de una empresa pueden demandar a los administradores por los daños y perjuicios causados por dolo, abuso de facultades, negligencia grave o incumplimiento de la ley o del contrato social, y también responderán frente a los acreedores de la compañía y a los socios de ésta, cuando hubieren lesionado directamente los intereses de cualquiera de ellos (Art. 128). Igualmente, los accionistas responderán ante los acreedores en la medida en que hubieren percibido pagos de la misma con infracción de las disposiciones de la LC; aunque no será aplicable cuando de buena fe hubieren percibido los socios cantidades como participación de beneficios (Art. 220). Asimismo, las resoluciones de la Asamblea serán nulas cuando ella dicte disposiciones que violaren la protección de los acreedores (Arts. 221 y 247.5). Estas normas parecen defender de forma adecuada los intereses de los acreedores, pero debemos resaltar que los acreedores no pueden convocar una Junta General, ni siquiera para la aprobación del balance anual. Exclusivamente, "los accionistas que representen por lo menos el $25 \%$ del capital social podrán pedir, por escrito, en cualquier tiempo, al administrador o a los organismos directivos de la compañ́a, la convocatoria a una Junta para tratar de los asuntos que indiquen en su petición; y si el administrador o el organismo directivo rehusare hacer la convocatoria o no la hicieren dentro del plazo de 15 días, contados desde el recibo de la petición, podrán recurrir al Superintendente de Compañías, solicitando dicha convocatoria" (Art. 213; vid. Art. 119). En otras legislaciones, los accionistas pue- den convocara a una Junta de Accionistas con un porcentaje mínimo de acciones ${ }^{142}$, e incluso demandar subsidiariamente a los administradores 143 .

\section{Conclusiones y Recomendaciones}

\section{Conclusiones}

El actual Código Ecuatoriano de Buen Gobierno Corporativo (CEc) presenta 51 recomendaciones de buen gobierno corporativo. Es un primer paso positivo, aunque las recomendaciones son meramente simples invitaciones - "música celestial", al carecer de un carácter vinculatorio y obligatorio para los empresarios, directores y accionistas de control. Dichas recomendaciones sólo se convierten en mandato para aquellas compañías que las implementen en sus estatutos sociales; pero aún ésta protección es muy débil, puesto que nada impide a que el accionista de control o una simple mayoría de socios reforme los estatutos a su conveniencia cuando lo estime conveniente a su gusto o arbitrio, para no cumplir las disposiciones estatutarias. Incluso en nuestro país, donde la violación de las normas estatutarias no es sancionada, ya que con los actuales medios disponibles a los accionistas de minoría, es imperioso gozar de legitimidad activa para demandar a la sociedad; no hablemos si quiera de demandar a los bloques de control.

La falta de adecuados controles corporativos disponibles a los accionistas minoritarios genera grave indefensión de sus legítimos intereses. Inclusive, los accionistas son acreedores de última (sexta) categoría ${ }^{144}$.

En materia de mercado de valores, nuestro país todavía está "en pañales" frente a otros países latinoamericanos, no hablar siquiera de mercados más desarrollados. Una adecuada regulación normativa de la legislación societaria y de mercado de valores, encaminada a la protección de los accionistas minoritarios, en resumen, un mejor gobierno corporativo, sí otorga mayores incentivos para ampliar y desarrollar el mercado de capitales.

\section{Recomendaciones}

\section{Respecto de los Accionistas}

- Los accionistas minoritarios deben poseer el derecho de elegir al menos a uno de los comisarios, y a un miembro del órgano de administración.

- Todos los derechos de los accionistas de minoría deben ser accesibles a todos los accionistas minoritarios; es decir, que los porcentajes mínimos para ejercer algunos derechos de minoría deben ser eliminados, en especial, el de la impugnación de los actos sociales y de la ASR.

- Al requerirse una sola acción para entablar la ASR o impugnación, se eliminaría el elevado depósito de valores, y así evitar el freeze-in de los socios peticionarios.

- Los administradores deben tener la carga de la prueba por sus posibles faltas de gestión. 
- La transacción de la responsabilidad de los administradores por la Junta General debe requerir de aprobación judicial, donde el juez debe verificar que el acuerdo se otorga en el mejor beneficio de la compañía. A su vez, el ADC o cualquier accionista no podrá votar si tiene algún conflicto de interés con el gestor y la empresa.

- Tiene que eliminarse que los únicos que pueden apelar y casar la sentencia, que impone la responsabilidad de los gestores, sean los propios administradores (Art. 249).

- Del mismo modo, debe descartarse el Art. 264 de la LC, que extingue la responsabilidad de los administradores cuando ellos hagan constar su inconformidad de una decisión a los comisarios; y, el Art. 216.11 del CPC que declara que no son testigos idóneos por falta de imparcialidad, "el socio por su coasociado o por la sociedad".

- Debe crearse un mecanismo que habilite el derivative suit.

- Debe permitirse la acción de clase o de grupo (class action suit), para casos societarios.

\section{Respecto de la Junta General}

- Prohibir el voto de los accionistas, por sí o por interpuesta persona, cuando tengan conflictos de intereses directos o indirectos.

- En caso de haber existido el voto de los accionistas en disyuntiva, la resolución es nula si perjudica a la sociedad o a los demás accionistas; y la carga de la prueba se invierte, donde el accionista con posible conflicto debe probar que fue tomada y ejecutada en el mejor interés de la compañía.

- Permitir el voto a distancia, como es el sufragio por medios telemáticos.

- La creación de un reglamento claro de la Junta General.

\section{Respecto de los Administradores}

- En sociedades supercapitalizadas, por Ley debería existir un Directorio u órgano semejante.

- El Directorio de una sociedad supercapitalizada debe estar conformado por al menos 3 miembros y con un máximo de 11; con sus correspondientes suplentes. La mitad más uno deben ser directores independientes y externos.

- Los accionistas de minoría deben tener la facultad de nombrar al menos un Director; y sólo ellos o el juez competente pueden revocar su cargo.

- El gerente general (CEO) no debe ser parte del Directorio, pero debe participar en él siempre que lo exija el organo de administración.

- El Director que disienta de una decisión "importante", o que una resolución pueda causar un daño grave e irreparable a la sociedad, debería tener él el deber de recu- rrir ante la justicia ordinaria para impedir la consecución de la decisión de la mayoría, ya sea del Directorio o de la Junta.

- Divulgación obligatoria de las actas y resoluciones de Directorio.

- Tiene que definirse con claridad un deber de lealtad.

- Debe prohibirse a los administradores asistir, participar o influir a los demás administradores o socios en las reuniones para decidir sobre operaciones o acuerdos cuando tengan conflicto de intereses.

- Los administradores son responsables de los daños y perjuicios por violación de sus deberes fiduciarios.

- Tiene que limitarse la información reservada que pueden acordar el $75 \%$ de los administradores (LMV Art. 26); y los hechos generales deben ser informados al regulador de bolsa.

- La creación de un reglamento del Directorio.

\section{Respecto de los Comisarios}

- Los comisarios deben ser externos e independientes del consejo de administración, de la sociedad y de los ADC.

- Los comisarios deben estar prohibidos de ser accionistas de la compañía o sus sucursales-filiales, y que no hayan tenido cargo alguno en la sociedad con 3 años de anticipación al nombramiento, y tampoco pueden poseer "partes beneficiarias".

- La remuneración de los comisarios no puede ser determinado en relación al desempeño de la compañía.

- Los accionistas de minoría deben poseer el derecho de nombrar a un comisario; y éste sólo puede ser removido por esta minoría.

- Debe ser obligatorio la creación de un comité de auditoría y de un comité de nominación-retribución, conformado en exclusiva por Directores independientes y Comisarios independientes.

- Los comisarios deben tener las mismas responsabilidades que los administradores, frente a los accionistas y frente a terceros.

- Los comisarios deberían acudir obligatoriamente a todas las reuniones del Directorio y de la JG.

\section{Respecto de los Acreedores}

- Los acreedores deben tener acceso a la misma información disponible para los accionistas (Arts. 15 y 248 de la LC; Arts. 13 y ss. de la LMV).

- Los acreedores deben gozar de legitimidad activa para iniciar una ASR y la impugnación de los acuerdos sociales, sin otro requisito que demostrar la deuda con la sociedad y el posible riesgo que puede acarrear para sus intereses las decisiones tomadas por los órganos corporativos.

- Asimismo, debe ampliárseles la legitimidad para los ya recomendados derivative suit y class action. 


\section{GRÁFICO 1}

Capitalización de los Mercados de Capital en países industrializados y el número de Compañías

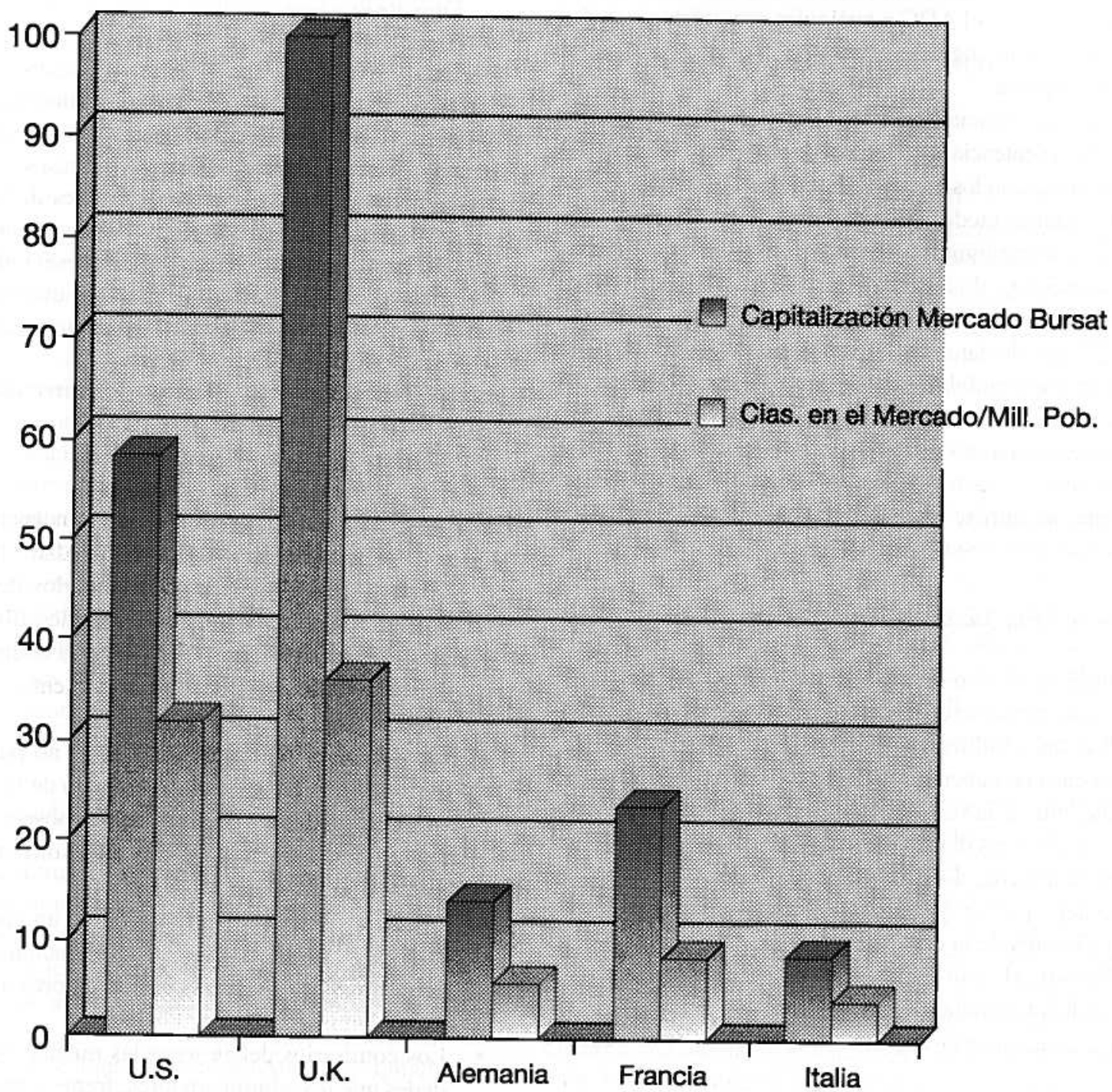

Fuente: MORCK Randall, BERNARD Yeung and WAYNE Yu, The Information Content of Stock Markets: Why Do Emerging Markets Have Synchronous Stock Price Movements? Journal of Financial Economics 58, 215-60 (2000)

\section{Abreviaturas}

\begin{tabular}{|l|l|}
\hline ADC & Accionista de Control \\
ASR & Acción Social de Responsabilidad \\
CAGC & Código Andino de Gobierno Corporativo \\
CEc & Código Ecuatoriano de Buen Gobierno Corporativo \\
CC & Código Civil \\
CCom & Código de Comercio \\
CPC & Código de Procedimiento Civil \\
ESP & España \\
LC & Ley de Compañias \\
OECD & Organización para la Cooperación y el Desarrollo Económico \\
STS & Sentencia del Tribunal Supremo Español \\
\hline
\end{tabular}


Notas 1 Vid. p.e. Comisión Andina de Juristas, Cronología Andina - Ecuador (XIl-1999), http://www.cajpe.org.pe/cronolog/dicec3.htm: "Luego de casi dos meses de investigaciones, la Comisión de Control Cívico de la Corrupción censuró la aceptación por parte de la campaña presidencial de Jamil Mahuad de 3.1 millones de dólares de Fernando Aspiazu y canalizados por él, cuando el mencionado ciudadano era propietario de uno de los bancos más grandes del país (Banco del Progreso) y había comprado una empresa que mantiene un litigio de cuentas con el Estado (Emelec)".

2 El 9-I-2000, el Dr. Jamil Mahuad W. adoptó la dolarización como moneda de curso legal; ésta decisión fue ratificada el 22-I-2000 por el nuevo Presidente de la República, Dr. Gustavo Noboa B.

3 Vid. sobre la crisis económica, p.e.: ACOSTA Alberto, Ecuador, ¡La dolarización es una bomba de tiempo!, 25-X-2002 http://www.revistainterforum.com/espanol/articulos/ 110302 neg_dolar_ecuador.html; BUSTAMANTE Fernando, Economía, política y familia en la sociedad ecuatoriana: en torno a una crisis bancaria en Ecuador, DEBATE $N^{\circ} 53$, visitado 11-VI-2005. http://www.dlh.lahora.com.ec/paginas/debate/paginas/debate213.htm; RUIZ ALONSO María José, Ecuador se levanta contra su peor crisis económica, América Economía, http://www.americaeconomica.com/repor/reportecuador.htm; visitado 12-II2005.

4 Art. 257 del Código Penal (CP): Serán reprimidos con reclusión mayor ordinaria de 4 a 8 años, los servidores de los organismos y entidades del sector público y toda persona encargada de un servicio público, que hubiere abusado de dineros públicos o privados [...]. Art. 257A del CP (Incorporado por el Art. 20 de la Ley 1999-26): Serán reprimidos con reclusión de 4 a 8 años las personas descritas en el artículo anterior que, abusando de sus calidades, hubieren actuado dolosamente para obtener o conceder créditos vinculados, relacionados o intercompañías, violando expresas disposiciones legales respecto de esta clase de operaciones. La misma pena se aplicará a los beneficiarios que dolosamente hayan intervenido para el cometimiento de este ilícito y a quienes hayan prestado su nombre para beneficio propio o de un tercero.

Además, los casos más sonados por la quiebra bancaria, posterior detención y privación de la libertad, son los de Alejandro Peñafiel y Fernando Aspiazu.

5 EELLS Richard Sedric, The meaning of modern business: an introduction to the philosophy of large corporate enterprise, Columbia University Press, New York (1960)

6 SHLEIFER Andrei and VISHNY Robert W., A Survey of Corporate Governance, 52 Journal of Finance 737 (1997). En el mismo sentido ISKANDER Magdi, MEYERMAN Gerald, GRAY Dale and HAGAN Sean, Corporate restructuring and governance in East Asia, Finance and Development 36 (1999)

7 ZINGALES Luigi, Corporate Governance, The New Palgrave Dictionary of Economics and Law (1998)

8 Vid. AA.VV., Diccionario Jurídico (2002) pp. 371-372.

9 Ley de Compañías; LC R.O. 312, de 5-XI-1999.

10 Ley de Mercado de Valores; LMV Ley 107, R.O. 367, de 23-VII-1998.

11 Codificación de la Ley General de Instituciones del Sistema Financiero; LGISF (10-I2001), Ley 2002-67 R.O. 250, de 23-I-2001; Comisión de Legislación y Codificación, de 10-I-2001.

12 Vid. p.e. Normas para la presentación de los estados financieros consolidados de acuerdo con la norma ecuatoriana de contabilidad no. 19 y auditados de acuerdo con las normas ecuatorianas de auditoría, R.O. 33, de 5-III-2003, Res. 03.Q.ICI.002; Resolución para aumento de capital de sociedades extranjeras al menos US\$2000, Res. SC.ICQ.2004.

13 Vid. p.e. Reglamento de Funcionamiento del Consejo Nacional de Valores (CNV) 1 R.O. 353 de 4-I-2000; Reglamento de Inscripción en el Registro del Mercado de Valores y de la Información Pública, Resolución CNV 93-002.

14 Código de Comercio; CCom R.O. Sup 1202, de 20-VIII-1960.

15 Código Civil; CC R.O. Sup 46, de 24-VI-2005.

16 P.e. Estatutos de la Corporación Civil Bolsa de Valores de Quito (BVQ), 3-X-2002.

17 Alemania, German Corporate Governance Code o The Cromme Code (26-II-2002 y 21V-2003)

18 Australia, Principles of Good Corporate Governance and Best Practice Recommendations (III-2003); A guide for fund managers and corporations (1-XII-2002); Horwath Corporate Governance Report (2002)

19 Bangladesh, The Code of Corporate Governance (III-2004)

20 Brasil, Code of Best Practice of Corporate Governance (30-III-2004); Recomendações sobre Governança Corporativa (VI-2002)

21 China, Code of Corporate Governance for Listed Companies (7-I-2001)

22 Colombia, Principios y Marco de referencia para la elaboración de un código de buen gobierno corporativo (VIII-2002) 
Notas 23 España, El Informe de la Comisión Especial para el fomento de la transparencia y seguridad en los mercados y en las sociedades cotizadas o Informe Aldama (8-I-2003); el Informe y Código Olivencia, el Gobierno de las sociedades cotizadas (26-II-1998); la Comisión Especial para el estudio de un Código Ético de los Consejos de Administración de las Sociedades (28-II-1997)

24 Francia, Recommandations sur le gouvernement d'entreprise (III-2004); The Corporate Governance of Listed Corporations (X-2003); Promoting Better Corporate Governance In Listed Companies (23-IX-2002); Vienot II Report (VII-1999); Vienot I Report (VI-1995)

25 Italia, il Codice di Autodisciplina delle società quotate rivisitato (VII-2002); The Preda Code o Report \& Code of Conduct (X-1999)

26 Japón, Principles of Corporate Governance for Listed Companies (16-IV-2004)

27 México, Código de Mejores Prácticas Corporativas (VII-1999)

28 Los Países Bajos, SCGOP Handbook of Corporate Governance (2004); The Dutch corporate governance code (9-XII-2003)

29 Perú, Principios de Buen Gobierno para las Sociedades Peruanas (VII-2002); Código de Buen Gobierno Corporativo para Empresas Emisoras de Valores (XI-2001)

30 Reino Unido, The Combined Code on Corporate Governance (23-VII-2003); También, CACG Guidelines: Principles for Corporate Governance in the Commonwealth (XI1999)

31 La UE aprobó el Informe Winter, Report of the high level group of company law experts on a modern regulatory framework for company law in Europe (2002)

32 Sarbanes-Oxley Act of 2002, Pub. L. No. 107-204, 116 Stat. 745, 30-VII-2002.

33 El CEN se constituyó en Quito (VI-2004) y está integrado por las bolsas se Valores de Guayaquil y Quito, los principales gremios de la producción en los sectores industrial, comercial y de la construcción, por las superintendencias de Compañías y de Bancos, la Asociación de Bancos Privados, el Fondo de Solidaridad, la Asociación de Compañías Administradoras de Fondos y Fideicomisos, la Asociación de Mutualistas, la Asociación de Casas de Valores ASOCAVAL, etc.; la Bolsa de Valores de Quito ejerce la secretaría técnica del CEN. Vid. también, Diario La Hora, Quito - Lunes, 13-VI-2005; http://www.lahora.com.ec/noticiacompleta.asp?noid=270904

34 Vid. Comunidad Andina, Prensa, visitado 1-VI-2005, http://www.comunidadandina.org/prensa/noticias/17-1-05.htm

35 Vid. White Paper sobre Gobierno Corporativo en América Latina, elaborado por la OECD (2004) p.4

36 Vid. BERGLOF Erik, A Note on the Typology of Financial Systems, in Comparative Corporate Governance: Essays and Materials 151-164, Klaus J. Hopt and Eddy Wymeersch eds. (1997)

37 Vid. p.e. DELAVENNE Francoise, Open-End Mutual Funds in France, in Funds and Portfolio Management Institutions: An International Survey, Stefano Preda ed. (1991); JENKINSON T, and LJUNGQVIST A. P., Going Public: The Theory and Evidence on How Companies Raise Public Finance, Oxford, Oxford University Press (2001); ADAMS Michael, Cross Holdings in Germany, 155 J. Institutional \& Theo. Econ, 80 (1999); GILSON Ronald J., Globalizing Corporate Governance: Convergence of Form or Function, 49 American Journal of Comparative Law 329 (2001)

38 YEOL KWON Jae, The Internal Division of Powers in Corporate Governance: A Comparative Approach to the South Korean Statutory Scheme, 12 Minn. J. Global Trade 299 (2003)

39 Vid. p.e. MILHAUPT Curtis J., Symposium Norms \& corporate law: creative norm destruction: the evolution of nonlegal rules in Japanese corporate governance, $149 \mathrm{U}$. Pa. L. Rev. 2083 (2001), p. 2090; GILSON Ronald J. and ROE Mark J., Understanding the Japanese Keiretsu: Overlaps between Corporate Governance and Industrial Organization, 102 YALE L.J. 871, 899 (1993); HOSHI Takeo, Japanese Corporate Governance as a System, en Comparative corporate governance: the state of the art and emerging research, Hopt Klaus J. et al. eds. (1998); GILSON Ronald J. \& ROE Mark J., Lifetime Employment: Labor, Peace, and the Evolution of Japanese Corporate Governance, 99 Colum. L. Rev. 508 (1999). MILHAUPT Curtis J., A Relational Theory of Japanese Corporate Governance: Contract, Culture, and the Rule of Law, 37 HARV. INT'L Law Journal 3 (1996)

$40 \mathrm{Cf}$. BECHT Marco and BOEHMER Ekkehart, Ownership and Voting Power in Germany, in The Control of Corporate Europe, preliminary version, available at www.ecgn.ulb.ac.be/book (10-V-2002). También vid. BURKART Mike, ELLINGSEN Tore y GIANNETTI Mariassunta, What You Sell is what You Lend? Explaining Trade Credit Contracts, ECGI - Finance Working Paper 71 (2005) http://papers.ssrn.com/sol3/papers.cfm?abstract_id $=618544$

41 DIETL Helmut M., Capital Markets and Corporate Governance in Japan, Germany, and the United States (1998) pp. 122 - 126. Los países germanos mantienen Consejos de Ad- 
ministración de dos niveles, que separan las funciones de supervisión y gestión en diferentes organismos. Este sistema dual, por lo general cuentan con un "Consejo de Supervision" compuesto por miembros no ejecutivos del Consejo, y un "Consejo de Administración" formado en su totalidad por directivos.

42 Vid. MASAHIKO Aoki, The Japanese Firm as a System of Attributes: A Survey and Research Agenda, in The Japanese Firm: The Sources of Competitive Strength, Masahiko Aoki \& Ronald Dore eds. (1994)

43 LA PORTA Rafael, LOPEZ-DE-SILANES Florencio, SHLEIFER Andrei and VISHNY Robert W., Law and Finance, Journal of Political Economy, 106 (1998)

44 See e.g. LANE Timothy et al., IMF- Supported Programs in Indonesia, Korea, and Thailand, Int'l Monetary Fund Occasional Paper No. 178 pp. $72-73$ (1999); Asia Pacific Talks Vow Tough Action on Economic Crisis, N.Y. Times, Nov. 26, 1997, p. Al; Bratton WiIliam A. and McCahery Joseph A., Comparative Corporate Governance and the Theory of the Firm: The Case Against Global Cross Reference, 38 J. Col. J.Transnat'l L. 213, 236, 238 (1999) pp. 213, 236, 238.

45 FANTO James A., The Role of Corporate Law in French Corporate Governance, 31 Cornell Int'l L.J. 31 (1998)

46 Vid. EDWARDS Jeremy and FISHER Klaus, Banks, Finance and Investment in Germany (1994); citado por BROWN J. Robert, Jr., Of Brokers, Banks and the Case for Regulatory Intervention in the Russian Securities Markets, 32 Stan. J Int'1 L. 185 (1996). También vid. BLACK Bernard and GILSON Ronald, Venture Capital and the Structure of Capital Markets: Banks Versus Stock Markets, 47 J. Fin. Econ. 47 (1998)

47 Vid. ROE Mark J., Political Preconditions to Separating Ownership from Corporate Control, 53 Stanford Law Review 539 (2000)

48 ROE Mark J., Strong Managers, Weak Owners: The Political Roots of American Corporate Finance (1994) p. 256.

49 ROE Mark J., Political Preconditions to Separating Ownership from Corporate Control, 53 Stanford Law Review 539 (2000)

50 ROE Mark J., A Political Theory of American Corporate Finance, 91 Colum. L. Rev. 10 (1991)

51 Vid CANTILLO Simon Miguel, The Rise and Fall of Bank Control in the United States, 88 Am.Econ. Rev. 1077 (1998) pp. 1077 - 1079

52 Cf. COFFEE John C. Jr., The Rise of Dispersed Ownership: The Role of Law in the Separation of Ownership and Control, 111 Yale Law Journal 1 (2001b). También véase, COFFEE John C. Jr., Symposium Norms and Corporate Law: Do Norms Matter? A Cross-Country Evaluation, 149 U. Pa. L. Rev. 2151 (2001c); BLACK Bernard and COFFEE John C., Jr., Hail Britannia? Institutional Investor Behavior under Limited Regulation, 92 Mich. L. Rev. (1997)

53 LA PORTA Rafael, LOPEZ-DE-SILANES Florencio and SHLEIFER Andrei (LA PORTA et al.), What Works in Securities Laws?, Working Paper Harvard University and NBER Working Paper No. 9882 (2003); WATSON Alan, Legal Transplants: An approach to Comparative Law, Charlottesville, VA: University of Virginia Press (1974). Cabe resaltar, que dichas tradiciones legales en el mundo se dividen en dos grupos: los países del sistema jurídico anglosajón o common law, y los países del sistema jurídico civilista o civil law, donde estos últimos a su vez se subdividen en el sistema germánico, escandinavo, francés y socialista; Vid. GLAESER Edward and SHLEIFER Andrei, Legal Origins, Q. J. Econ. 117 (2002): Mayormente aceptada es la división en estas cinco origines de las tradiciones legales: English, German, Scandinavian, French and Socialist legal origins.

54 Vid. Id.

55 Vid. LA PORTA et al., What Works in Securities Laws?, Working Paper Harvard University and NBER Working Paper No. 9882 (2003); LA PORTA et al., Investor Protection and Corporate Valuation, Journal of Finance (2002)

56 Vid. COFFEE John C. Jr., Privatization and Corporate Governance: The Lessons from Securities Market Failure, 25 J. Corp. L. 1, 1 (1999b)

57 Vid. LA PORTA et al., Investor Protection and Corporate Valuation, Journal of Finance (2002); LA PORTA et al., Legal Determinants of External Finance, 52 Journal of Finance, 1131 (1997). También, Also, SHLEIFER Andrei and WOLFENZON Daniel, Investor Protection and Equity Markets (April 2, 2002)

58 Vid. LA PORTA et al., Corporate Ownership Around the World, 54 Journal of Finance, 471 (1999)

59 Vid. NENOVA Tatiana, The Value of Corporate Votes and Control Benefits: A Crosscountry Analysis (SSRN Working Paper (2000)), available at :papers.ssrn.com/sol3/papers.cfm?abstract_id=237809

60 Vid. p.e. COFFEE John C. Jr., Symposium Norms and Corporate Law: Do Norms Matter? A Cross-Country Evaluation, 149 U. Pa. L. Rev. 2151 (2001). De acuerdo con Step- 
hen J. CHOI (2002), John COFFEE Jr. acuño el término "law matters" en Privatization and Corporate Governance: The Lessons from Securities Market Failure (1999).

61 Vid. COFFEE John C. Jr., The Future as History: The Prospects for Global Convergence in Corporate Governance and its Implications, 93 Northwestern U. Law Rev. (1999); e CHEFFINS Brian R., Corporate Law and Ownership Structure A Darwanian Link? (2002)

62 BLACK Bernard, Is Corporate Law Trivial?: A Political and Economic Analysis, 84 NW. U. L. Rev. 542 (1990b)

63 EASTERBROOK Frank H., International Corporate Differences: Market or Law?, Journal of Applied Corporate Finance 9 (1997)

64 See LESSIG Lawrence, Social Meaning and Social Norms, 144 U. Pa. L. Rev. 2181 (1996); CHEFFINS Brian R., Does Law Matter?: The Separation of Ownership and Control in the United Kingdom (2000)

65 SMITH Adam, An Inquiry into the Nature and Causes of the Wealth of Nations. Chicago, IL, University of Chicago Press (1776, [1976])

66 BERLE Adolf and MEANS Gardiner C., The Modern Corporation and Private Property, MacMillan, New York (1932); Revised Ed. Harcourt, Brace \& World (1968)

67 LA PORTA et al., Corporate ownership around the world, Journal of Finance 54, 471-517 (1999)

68 Vid. p.e. LA PORTA et al., Investor Protection and Corporate Valuation, The Journal of Finance, LVII 3 (2002)

69 Sin embargo cabe destacar que importantes empresas estadounidenses como Wal-Mart y Ford Co. poseen una 'familia de control' que además tienen lazos de parentesco con los Consejeros Ejecutivos. Lo mismo sucede en UK.

70 HANSMANN Henry and KRAAKMAN Reinier, The End of History for Corporate Law, 89 Georgetown Law Journal 439 (2001) p. 469, standard shareholder-oriented model of the corporate firm; Vid. tambien MILHAUPT Curtis J., The Evolution Of Nonlegal Rules In Japanese Corporate Governance, Symposium Norms \& Corporate Law: Creative Norm Destruction, 149 U. Pa. L. Rev. 2083 (2001); BLAIR Margaret M. and STOUT Lynn A., A Team Production Theory of Corporate Law, Virginia Law Review 85 Va. L. Rev. 247 (1999)

71 US Revlon, Inc. v. MacAndrews \& Forbes Holdings, Inc., 506 A.2d 173, 176 n.3 (Del. 1986)

72 ROMANO Roberta, A Cautionary Note on Drawing Lessons from Comparative Corporate Law, 102 Yale Law Journal 2021 (1993)

73 Vid. p.e. BAINBRIDGE Stephen M., The Globalization of Corporate and Securities Laws in the Twenty-first Century: Director v. Shareholder Primacy in the Convergence Debate, 16 Transnat'l Law 45 (2002)

74 U.S. Katz v. Oak Indus Inc., 508 A.2d 873, 879 Del. Ch. 1989

75 Vid. BAINBRIDGE Stephen M., Independent Directors and the ALI Corporate Governance Project, 61 Geo. Wash. L. Rev. 1034 (1993); también vid. MILLON David, New Game Plan or Business as Usual? A Critique of the Team Production Model of Corporate Law, 86 Va. L. Rev. 1001, 1003 (2000)

76 Alejandro BÉRGAMO, Sociedades Anónimas (Las Acciones), Madrid (1970) Tomo I, CAP VI, p. 10.

77 Vid. Arts. 117 y 138 del CCom. Vid. Representación en sociedad mercantil, Gaceta Judicial año XXV, Serie 4 No. 194, p. 1554 (Quito, 23-X-1925); Factores de comercio, Gaceta Judicial año XXXVII, Serie V No. 151, p. 3670 (Quito, 29-VII-1938); Factor mercantil, Gaceta Judicial año LXXV, Serie XII No. 7, p. 1516 (Quito, 16-XII-1974). Vid. también, CC Art. 1992: [...] Es sociedad colectiva aquella en que todos los socios administran por si o por un mandatario elegido de común acuerdo.

78 Art. 231.1 de la LC: [...] Es de competencia de la junta general: Nombrar y remover a los miembros de los organismos administrativos de la compañía, comisarios, o cualquier otro personero o funcionario cuyo cargo hubiere sido creado por el estatuto, y designar o remover a los administradores, si en el estatuto no se confiere esta facultad a otro organismo. Similar es p.e. la designación de albacea testamentario (Art. 1315 y ss. del CC).

79 Vid. Alejandro BÉRGAMO, Sociedades Anónimas (Las Acciones), Madrid (1970) Tomo I, CAP VI, p. 14.

80 Vid. Id. pp. 15 y 16.

81 Art. 144 de la LC; vid. también, Art. 2020 y ss. del CC; Arts. 117 y 138 del CCom.

82 Art. 144 de la LC: La sociedad anónima se administra por mandatarios amovibles; Art. 150 de la LC: La escritura de fundación contendrá: [... . 8. La forma de administración y las facultades de los administradores; 10.: La forma de designación de los administradores y la clara enunciación de los funcionarios que tengan la representación legal de la compañía; Art. 252. La Superintendencia de Compañías no aprobará la constitución de 
una compañía anónima si del contrato social no aparece claramente determinado quién o quiénes tienen su representación judicial y extrajudicial. Esta representación podrá ser confiada a directores, gerentes, administradores u otros agentes. Si la representación recayere sobre un organismo social, éste actuará por medio de un presidente.

83 Art. 251 de la LC: El contrato social fijará la estructura administrativa de la compañía; Art. 253: La representación de la compañía se extenderá a todos los asuntos relacionados con su giro o tráfico, en operaciones comerciales o civiles, incluyendo la constitución de prendas de toda clase. El contrato podrá limitar esta facultad [...]; También, el Art. 231.1

84 Vid. Tribunal Distrital de lo Fiscal, $1^{2}$ Sala en Quito, 14-III-1986; caso Compañía La Portuguesa S. A. contra el Director General de Rentas.

85 Vid. Art. 59 y ss. de la LC. Art. 59: La compañía en comandita simple existe bajo una razón social y se contrae entre uno o varios socios solidaria e ilimitadamente responsables y otro u otros, simples suministradores de fondos, llamados socios comanditarios, cuya responsabilidad se limita al monto de sus aportes.

86 Art. 65 de la LC: Salvo pacto en contrario, la designación de administradores se hará por mayoría de votos de los socios solidariamente responsables y la designación sólo podrá recaer en uno de éstos. Además, el Art. 64 de la misma norma: Cuando en una compañía en comandita simple hubiere dos o más socios nombrados en la razón social y solidarios, ya administren los negocios de la compañía todos juntos, o ya uno o varios por todos, regirán respecto de éstos las reglas de la compañía en nombre colectivo, y respecto de los meros suministradores de fondos, las de la compañía en comandita simple.

87 Art. 231.3: [corresponde a la JG] Fijar la retribución de los comisarios, administradores e integrantes de los organismos de administración y fiscalización, cuando no estuviere determinada en los estatutos o su señalamiento no corresponda a otro organismo o funcionario.

88 Vid. p.e. SANCHEZ-CALERO Guilarte, El interés social y los varios intereses presentes en la sociedad anónima cotizada, RDM, 246, oct-dic. (2002); URÍA Rodrigo, MENÉNDEZ M. Aurelio y MUÑOZ P. José, La junta general de accionistas, en Comentario al régimen legal de las sociedades mercantiles, dirigida por Uría, Menéndez y Olivencia, Ed. Civitas, Madrid T. V (1992); CACHÓN BLANCO José Enrique, Derecho del Mercado de Valores, Ed. Dykinson, Tomo I, Madrid, (1992)

89 Vid. p.e. UK "City Code" on Takeovers and Mergers.

90 Superintendencia de Compañías, Res. 02.Q.ICI.007 (23-IV-2002) R.O. 564: Reglamento para la calificación y registro de las personas naturales y jurídicas que ejerzan actividades de auditoria externa. Derogada Res. 87.1.6.3.00004 (20-III-1987) R.O. 652: Normas para la calificación y registro de las personas naturales y jurídicas que ejerzan actividades de auditoria externa.

91 Superintendencia de Compañías, Res. 02.Q.ICI.012 (11-VII-2002) R.O. 621: Normas sobre montos mínimos de activos en los casos de auditoría externa obligatoria. Derogadas Res. 02.Q.ICI.004 (26-III-2002) R.O 555: Normas sobre montos mínimos de activos para contratación de auditoria externa obligatoria. Derogadas Res. 87.1.6.3.00003 (20-III1987) R.O. 652, modificada por la Res 88.1.6.3.00011 (26-XII-1988) R.O. 101: Compañías, personas jurídicas y asociaciones, que están obligadas a someter sus estados financieros anuales al dictamen de auditoria externa.

92 Vid. International Accounting and Auditing Trends, Center for International Financial Analysis \& Research; quienes establecen un ranking de 90 elementos que se incluyen u omiten en la presentación de los estados financieros. También, vid. Jonathan HAY, Andrei SHLEIFER and Robert W. VISHNY, Toward a Theory of Legal Reform, European Economic Review 40 (May 1996) 559-67.

93 LGISF passim, Art. 1: "[...] la Superintendencia de Bancos, entidad encargada de la supervisión y control del sistema financiero [... tiene] la protección de los intereses del público". Vid. https://www.superban.gov.ec/ En el caso de los bancos privados, también están controlados por la Junta Bancaria y de manera indirecta por el Banco Central.

94 LMV Título II, Del Consejo Nacional de Valores; Título III, De las atribuciones y funciones de la Superintendencia de Compañías en el mercado de valores.

95 Vid. LA PORTA et al., What Works in Securities Laws?, Journal of Finance, forthcoming (2005); este trabajo hace una comparación entre 49 países, incluyendo Ecuador.

96 Cabe resaltar que los Estatutos sociales pueden establecer y agregar obligaciones a los accionistas; p.e. Art. 217: Ningún accionista podrá ser obligado a aumentar su aporte, salvo disposición en contrario de los estatutos. También, vid. ESP STS 18-III-2002, RJ 2002/2850, Recurso de Casación 3100/1996. Sin embargo, por el carácter apático, anónimo e impersonal de las sociedades anónimas bursátiles, éste supuesto es difícil que ocurra en sociedades abiertas.

97 El accionista debe aportar a la compañía la porción de capital por él suscrito y no desembolsado, en la forma prevista en el estatuto o, en su defecto, de acuerdo con lo que dispongan las juntas generales (Art. 218). 
98 Otra clasificación de los derechos de los accionistas puede ser: Por la subordinación a la voluntad colectiva colegiada; o por el modo de ejercicio. Vid. al respecto BÉRGAMO Alejandro, Sociedades Anónimas (Las Acciones), Prensa Castellana, Tomo I, Madrid (1970) quien a su vez cita exhaustivamente la doctrina alemana sobre el tema.

99 Vid. ESP SSTS 30-XI-1971, RJ 1971/5019; 10-X-1996, RJ 1996/7063; 19-III-1997, RJ $1997 / 1721$, entre otras.

100 Vid. McKinsey Global Investor Opinion Survey on Corporate Governance, Key Findings, Exhibits 1 to 4 (July 2002); disponible en: www.mckinsey.com

101 Art. 36 de la LMV. Toma de Control: Las personas naturales o jurídicas que directa o indirectamente deseen tomar el control de una sociedad, inscrita en el Registro del Mercado de Valores, sujeta al control de la Superintendencia de Compañías o de Bancos, sea mediante una o varias adquisiciones que individualmente o en conjunto impliquen la toma de control de una sociedad, deberán informar a la sociedad, al público y a cada una de las bolsas de la transacción que pretende efectuar, con una anticipación de por lo menos siete días hábiles a la fecha en que se efectuará la negociación. El C.N.V. normará el contenido y forma de la información que deberá proporcionar. Este aviso tendrá una vigencia de 30 días. En dicha información se indicará, al menos, el precio, plazo, término, forma de pago y demás condiciones de la negociación a efectuarse, cualquiera que sea la forma de adquisición de las acciones incluidas las que pudieran realizar por suscripción directa.

102Reglamento (CE) 2157/2001, del Consejo de 8-X-2001, por el que se aprueba el Estatuto de la Sociedad Anónima Europea (SE).

103 Vid. JUSTE MENCÍA Javier, Los Derechos de Minoría en la Sociedad Anónima, Ed. Aranzadi, Navarra (1995) p. 29: "Esta terminología ha sido empleada fundamentalmente en Italia".

104 Vid. p.e. SCHMIDT K., Gesellschaftsrecht, Berlín (1991) p. 385; WIEDEMANN, Gesellschaftsrecht, Manchen (1980); WILHELM Das neue Aktiengesetz, en AG 8 (1965) p. 217; Citados por JUSTE MENCÍA Javier, Los Derechos de Minoría en la Sociedad Anónima (1995) p. 70.

105En España éste derecho se denomina "información cualificada" (ESP STS 12-VI-1997).

106Vid. JUSTE MENDA Javier, Los Derechos de Minoría en la Sociedad Anónima, p. 142.

107 Albania, Commercial Companies Law (CCL) n. 7638, 19-XI-1992. Argentina, Código de Procedimiento Civil y Comercial Arts. 168, 169; Ley de Compañías Arts. 15, 54, 59, 254, $270,276,280,296,298$. Requiere el $5 \%$ de las acciones. Australia, Companies Act especially Pt 9.4B. Requiere 1 acción para iniciar la ASR. Austria, Ley de Sociedades Bursátiles (Aktiengesetz o AktG $\S \S 4,99,102$ - 124). Requiere aprobación de la JG. HongKong, Sect.5A Companies Ordinance (Vid Foss v. Harbottle (1843) UK). Vietnam, Ordinance on Procedure for settlement of economic disputes Arts. 12, 31, 33.

108ESP STS 1-III-2004, 158/2004, RJ 2004/802.

109 Vid. HURTADO COBLES José, La Responsabilidad de los Administradores Societarios en el Ámbito Civil y Social (Estudio de su problemática en la praxis judicial) Ed. Atelier, Barcelona (1998) p. 78.

110 Vid. POLO Eduardo, Los Administradores y el Consejo de Administración de la Sociedad Anónima (1992) pp. 130-134.

111 Vid. ESP Sentencia de la Audiencia Provincial (SAP) Baleares 437/2003 (Sección 5a) 13 X-2003 (JUR 204/75208)

112 Vid. ESP SSTS 28-II-1996, RJ 1996/1608; 27-XII-1996, RJ 1996/9377; 31-I-1997, RJ 197/254; 16-II-2004, RJ 2004/648, 87/2004, Recurso de casación 1345/1998.

113Francia, Código de Comercio Art. 225-120.

114 Vid. CPC aprobado el 26-IV-2005. Además vid. p.e. ESP SSTS 25-IV-1990, RJ 1990/2802; 26-XI-1993, RL 1993/9137; 21-VII-1998, RJ 1998/6746; 26-XI-1999, RJ $1999 / 8435$.

115 Vid. AA.VV. Comentarios a la Nueva Ley de Enjuiciamiento Civil, Barcelona (2000) T. I. pp. $821-829$.

116Art. 272 de la LC: La acción de responsabilidad contra los administradores o miembros de los consejos de administración, vigilancia o directorios, será entablada por la compañía, previo acuerdo de la Junta General, el mismo que puede ser adoptado aunque no figure en el orden del día. La JG designará a la persona que haya de ejercer la acción correspondiente. En cualquier momento la junta general podrá transigir o renunciar al ejercicio de la acción, siempre que no se opusieren a ello accionistas que representen la décima parte del capital pagado, por lo menos. El acuerdo de promover la acción o de transigir implica la destitución de los respectivos administradores.

117 Vid. LOJENDIO OSBORNE Ignacio, La Junta General de Accionistas (2003) p. 332. 118ESP Art. 117 de la LSA. 
119 Vid. La Constitución Política (1998) permite las acciones de grupo por la violación de derechos u obligaciones ambientales (Art. 9l)

120 Vid. p.e. EE.UU. Chancery Court Ch. Ct. R. 23.1; 8 Del. C. $\S 327$; Lewis v. Anderson, 477 A.2d 1040 (Del. 1984); Zapata Corp. v. Maldonado, 430 A.2d 779 (Del. 1981); Spiegel v. Buntrock, 571 A.2d 767 (Del. 1990); In re Oracle Corp. Deriv. Litig., Consol. C.A. No. 18751, Strine, V.C. (Del. Ch. June 13, 2003, revised June 17, 2003).

121 Vid. p.e. EE.UU. Chancery Court Ch. Ct. R. 23; TCW Technology Partnership Ltd. v. Intermedia Comm., Inc., C.A. Nos. 18336, 18289, 18293, (Del. Ch. Oct. 17, 2000); Gaffin v. Teledyne, 611 A.2d 467, 472 (Del. 1992); In re Triarc Companies, Inc. Class and Derivative Litig., 791 A.2d 872 (Del. Ch. 2001). Vid. p.e. ANGIOLILLO Bruce D., Settlement Issues In Securities Class Actions: The Defense Perspective Securities Litigation, Practicing Law Institute (2002); BARKIN Samuel L. and ZWEIFACH Lawrence J., Recent Developments in the Settlement of Securities Class Actions, 33rd Annual Institute on Securities Regulation, Practising Law Institute (2001); CHOI Stephen J., The Evidence on Securities Class Actions, UC Berkeley School (2004) SSRN Working Paper http://ssrn.com/abstract=528145; DREYFUSS Richard H., Class Action Judgment Enforcement In Italy: Procedural "Due Process" Requirements, 10 Tul. J. Int'l \& Comp. L. 5 (2002)

122El Art. 38 de la Ley de Modernización del Estado, R.O. S-144 (18-VIII-2000): Los tribunales distritales de lo Contencioso-Administrativo conocerán y resolverán de todas las demandas y recursos derivados de actos, contratos, hechos administrativos y reglamentos, expedidos, suscritos o producidos por las instituciones del Estado, salvo los derivados de controversias sometidas a mediación y arbitraje de conformidad con la ley. No se exigirá como requisito previo para iniciar cualquier acción judicial contra las instituciones del Estado el agotamiento o reclamo en la vía administrativa. Este derecho será facultativo del administrado, siempre y cuando lo ejerciera dentro del término de 90 días.

123 Vid. Art. 231 de la LC.

124Ecuador, Arts. 247, 253, 261, 263, 265 de la LC.

125España, Ley de Sociedades Anónimas LSA (1989) Art. 217.

126Egipto, Ley de Compañías Arts. 77 y 79.

127Finlandia, Companies Act, Section 9:1, 9:3.

128Japón, Código de Comercio, Arts. 260.2.1, 230-10.

129 Singapur, Companies Act, Section 216.

130US Kahn v. Tremont Corp., 694 A.2d 422, 428 (Del. 1997); Kahn v. Lynch Communication Sys., 638 A.2d 1110, 1117 (Del. 1994).

131 Nueva Zelanda, New Zealand Stock Exchange Listing Rules- NZSE LR 2.2.2, 9.1.1, 9.2.1, 6.1.2, 9.2.5, 10 .

132Vid. UK North-West Transportation Co Ltd v Beatty (1887) 12 App Cas 589: "A majority shareholder should not exercise its votes in a manner which discriminates against the minority so as to expropriate property rights".

133Vid. Arts. 207.4, 239, 241. También, CAGC medida 14; CalPERS principles (2005).

134La definición de administradores, consejeros, directivos debería incluir a los administradores de hecho y de derecho; términos incorporados p.e. en la Directiva 2003/6/CE, Art. 1: 1) Persona que ejerce un cargo directivo en un emisor: persona que es a) miembro de los órganos de administración, gestión o supervisión del emisor; b) responsable de alto nivel que, sin ser miembro de los órganos mencionados en la letra a) tiene habitualmente acceso a la información privilegiada relacionada, directa o indirectamente, con el emisor y competencia para adoptar decisiones de gestión que afecten al desarrollo futuro y a las perspectivas empresariales de ese emisor. 2) Persona estrechamente relacionada con una persona que ejerza un cargo directivo en un emisor de instrumentos financieros: a) el cónyuge de la persona que ejerza un cargo directivo o cualquier persona relacionada con ella considerada como equivalente al cónyuge por la legislación nacional; b) con arreglo a la legislación nacional, los hijos a cargo de la persona que ejerza un cargo directivo; c) otros parientes de la persona que ejerza un cargo directivo que vivan en su hogar por un período mínimo de un año; d) cualquier persona jurídica, fídeicomiso (trust) o asociación, en la que ocupe un cargo directivo una persona citada en el apartado 1 del presente artículo o en las letras (a) (b) y c) del presente apartado, o que esté directa o indirectamente controlada por esta persona, o que se haya creado para beneficio de esa persona, o cuyos intereses económicos sean en gran medida equivalentes a los de esa persona.

135Sobre ambos deberes fiduciarios: vid. p.e. ESP SSTS 28-II-1996, RJ 1996/1608; 22-VI1995, RJ 1995/5179; 25-V-1993, RJ 1993/3736; 4-XI-1991, RJ 1991/8143; SAP Baleares 13-X-2003, AC 437/2003 (JUR 2004/75208)

136Vid. LLEBOT MAJO José Oriol, Los Deberes de los Administradores de la Sociedad Anónima, Ed. Civitas, Madrid (1996) p. 38.

137Vid. SÁNCHEZ Aníbal, La Acción y los Derechos del Accionista (1994) p. 173. 


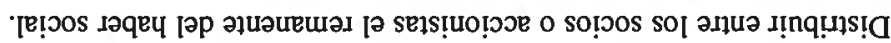

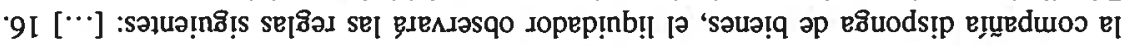

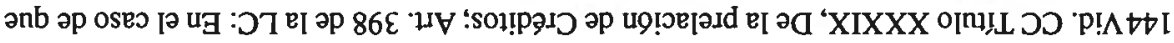

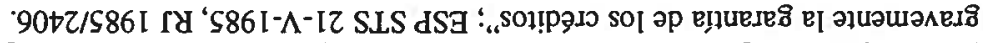

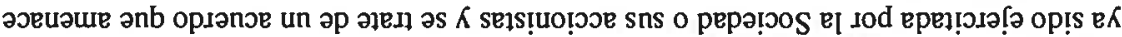

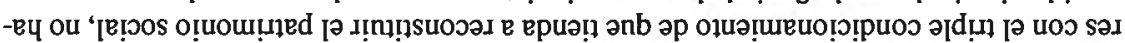

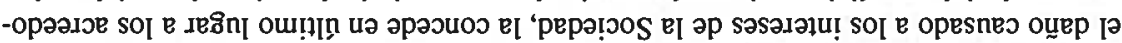

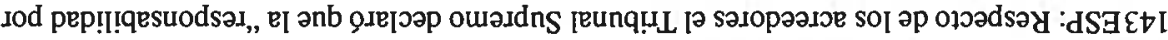

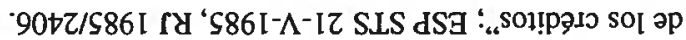

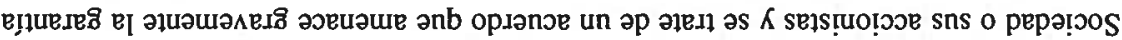

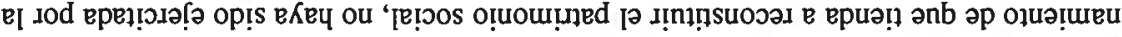

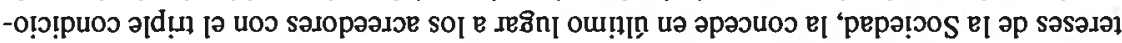

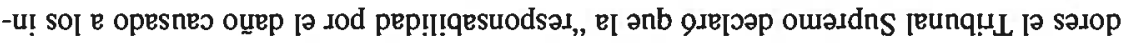

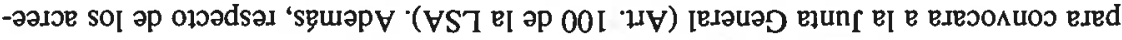

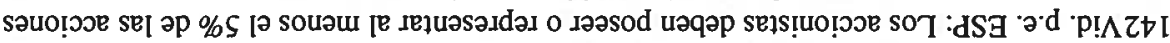

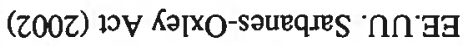

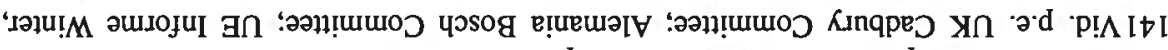

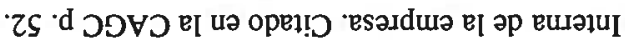

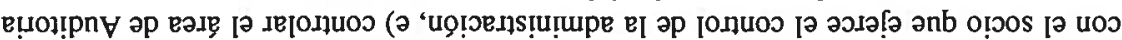

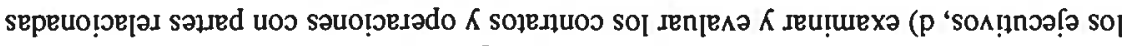

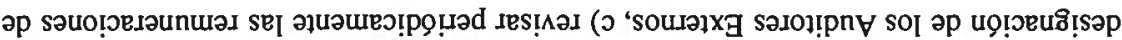
e[ se]s!luo!oว $ә$

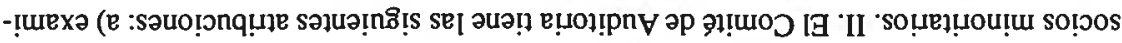

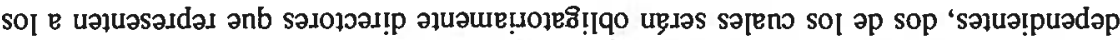

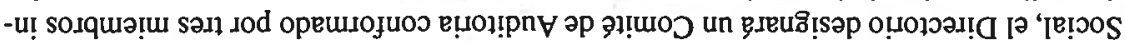

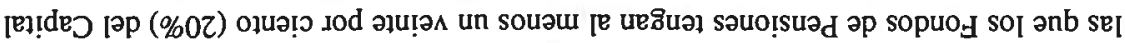

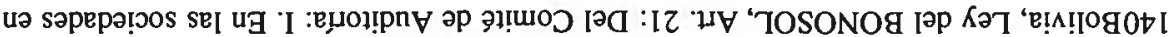

' $\supset \forall$ † 6 I

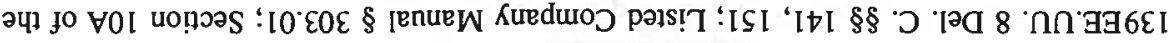

¿00Z

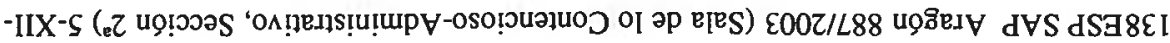

